OPEN ACCESS

Edited by:

Xiaoyong Yang

Yale University, United States

Reviewed by:

Alain Couvineau,

Institut National de la Santé et de la

Recherche Médicale (INSERM), France

Richard G. Hunter,

University of Massachusetts Boston,

United States

*Correspondence:

Gianfranco Umberto Meduri

gmeduri@uthsc.edu

Specialty section:

This article was submitted to

Molecular and Structural

Endocrinology,

a section of the journal

Frontiers in Endocrinology

Received: 23 December 2019

Accepted: 09 March 2020

Published: 22 April 2020

Citation:

Meduri GU and Chrousos GP (2020)

General Adaptation in Critical IIIness:

Glucocorticoid Receptor-alpha Master Regulator of Homeostatic Corrections.

Front. Endocrinol. 11:161.

doi: 10.3389/fendo.2020.00161

\section{General Adaptation in Critical Illness: Glucocorticoid Receptor-alpha Master Regulator of Homeostatic Corrections}

\author{
Gianfranco Umberto Meduri ${ }^{1,2 *}$ and George P. Chrousos ${ }^{3}$ \\ ${ }^{1}$ Division of Pulmonary, Critical Care, and Sleep Medicine, Department of Medicine, University of Tennessee Health Science \\ Center, Memphis, TN, United States, ${ }^{2}$ Memphis Veterans Affairs Medical Center, Memphis, TN, United States, ${ }^{3}$ University \\ Research Institute of Maternal and Child Health and Precision Medicine, National and Kapodistrian University of Athens, \\ Medical School, Athens, Greece
}

In critical illness, homeostatic corrections representing the culmination of hundreds of millions of years of evolution, are modulated by the activated glucocorticoid receptor alpha (GR $\alpha$ ) and are associated with an enormous bioenergetic and metabolic cost. Appreciation of how homeostatic corrections work and how they evolved provides a conceptual framework to understand the complex pathobiology of critical illness. Emerging literature place the activated $\mathrm{GR} \alpha$ at the center of all phases of disease development and resolution, including activation and re-enforcement of innate immunity, downregulation of pro-inflammatory transcription factors, and restoration of anatomy and function. By the time critically ill patients necessitate vital organ support for survival, they have reached near exhaustion or exhaustion of neuroendocrine homeostatic compensation, cell bio-energetic and adaptation functions, and reserves of vital micronutrients. We review how critical illness-related corticosteroid insufficiency, mitochondrial dysfunction/damage, and hypovitaminosis collectively interact to accelerate an anti-homeostatic active process of natural selection. Importantly, the allostatic overload imposed by these homeostatic corrections impacts negatively on both acute and long-term morbidity and mortality. Since the bioenergetic and metabolic reserves to support homeostatic corrections are time-limited, early interventions should be directed at increasing $\mathrm{GR} \alpha$ and mitochondria number and function. Present understanding of the activated GC-GR $\alpha$ 's role in immunomodulation and disease resolution should be taken into account when re-evaluating how to administer glucocorticoid treatment and co-interventions to improve cellular responsiveness. The activated $\mathrm{GR} \alpha$ interdependence with functional mitochondria and three vitamin reserves $(B 1, C$, and $D)$ provides a rationale for co-interventions that include prolonged glucocorticoid treatment in association with rapid correction of hypovitaminosis.

Keywords: critical illness, glucocorticoid receptor-alpha, nuclear factor- $\mathrm{k} B$, mitochondria, hypovitaminosis 


\section{CRITICAL ILLNESS, SPECIES EVOLUTION, AND INDIVIDUAL DEVELOPMENT}

The reasons behind the evolutionary success of mammals and other multicellular organisms is their extraordinary capacity to adapt to changing environmental conditions and survive by maintaining their homeostasis (1). Homeostasis refers to the relative stability in the activity of the physiological systems of the organism that are essential to support life (2). The process of maintaining stability within a harmless range via homeostatic physiologic corrections to both predictable and unpredictable adverse forces or stressors is termed "eustasis" (2). In the course of human evolution, homeostatic corrections have emerged to increase the host's ability to cope with adverse or even catastrophic events (3). These responses are shaped by trade-offs, sometimes with benefits and disadvantages in different periods of the life cycle (4). Following the Cambrian explosion, about 450 million years ago, when multicellular organisms-originally formed in water environments-colonized the land physiological homeostatic changes emerged to allow survival. These corrective changes were essential to mammalian species evolution and emerged to solve a frequent conflict between environmental changes and preservation of the individual allowing survival and, hence, reproduction. These alterations permitted progression to future generations i.e., survival of the species through the active process of natural selection (5). These corrections involved profound neural, metabolic and immune changes mediated by a few major physiological systems (e.g., the central nervous, autonomic, cardiorespiratory, endocrine, and immune systems), and acting through integrated crosstalk pathways, that was associated with appropriate responses throughout the organism (5). Such changes have been relatively conserved across many vertebrates, including mammalian species $(6,7)$. They have evolved to allow coping with lack of energy, dehydration, hemorrhage, infections, toxic substances, or relatively short-lived inflammatory responses, such as those of wound healing or exposure to foreign substances (7).

When the organism is exposed to stressors that exceed the harmless stability range, individual survival is maintained at the expense of this organism's health and longevity. This condition is different from healthy homeostasis or eustasis and is called "allo-stasis" or different (allo)-stasis or even more accurately "caco (bad) -stasis. The cumulative cost of cacostasis for the organism, has been called allostatic or cacostatic burden. Excessive or prolonged cacostatic burden results in severe acute and/or chronic cacostatic pathology $(2,8)$. The intensive care unit (ICU) stress state represents a new and very different ecosystem from those within which humans evolved in the past. Actually, critical illness epitomizes an acute and/or chronic cacostatic burden that goes beyond an evolutionarily conserved physiological adaptive response, and if left untreated it could rapidly exhaust homeostatic compensation and lead to death of an organism (lethal cacostasis). In critically ill patients, the need for vital organ support (maintenance of arterial blood pressure, mechanical ventilation, and other support measures, which were not available until the middle of the last century), reflects near exhaustion or exhaustion of (i) neuroendocrine homeostatic compensation, also known as "critical illness-related corticosteroid insufficiency" (CIRCI) (8); (ii) cell bio-energetic and other functions; and (iii) reserves of vital micronutrients (vitamins and minerals). Even when it allows survival of the patient, homeostatic failure, ranging in acuity and severity, has a major impact on morbidity and mortality during and after hospitalization. CIRCI-associated dysregulated systemic inflammation and mitochondrial dysfunction are central to the increased morbidity and mortality of acute and/or chronic critical illness and the subject of this review.

\section{INNATE IMMUNITY AND NUCLEAR FACTOR-KB}

In multicellular organisms, the innate immune system with its recognition and signaling mechanisms is the most ancient form of host defense to infectious and non-infectious threats during

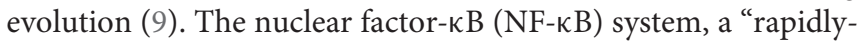
acting" primary transcription factor regulated cellular response, is a central activator of innate immunity. It appears that the NF- $\kappa \mathrm{B}$ was incorporated into this ancient signaling pathway more than 420 million years ago, and has been shown to play independent roles in vertebrate and insect lineages $(9,10)$. In most cell types, the inactive form of NF- $\mathrm{BB}$, a heterodimeric protein composed of the DNA-binding proteins p65 and p50, is retained in the cytosol by association with inhibitory factors, such as IкB proteins; when activated, the latter are rapidly phosphorylated and degraded via the proteasomal pathway, liberating NF- $\kappa \mathrm{B}$ and allowing it to translocate into the nucleus (11). In tumor necrosis factor- $\alpha$ (TNF- $\alpha$ )-stimulated HeLa cells, a genome-wide study identified 12,552 genome binding sites of p65 (12). Among the 1,667 distinct NF- $\mathrm{B}$ target genes identified, NF- $\mathrm{kB}$ controlled the expression of 249 target genes, including inflammatory cytokines, chemokines, inflammatory enzymes, adhesion molecules, and immune system receptors, which are known to orchestrate the integrated inflammatory and immune responses. Interestingly, an additional 626 identified $\mathrm{NF}-\kappa \mathrm{B}$ target genes were involved in metabolic processes (13).

In critical illness, NF- $\kappa \mathrm{B}$-driven systemic inflammation, also known as a "cytokine storm" (14), activates a multi-system response that includes at least three major domains: (i) the stress system composed by the hypothalamic-pituitary-adrenal (HPA) axis and the locus caeruleus-norepinephrine/sympathetic nervous system activated to provide sufficient energy and hemodynamic stability to overcome the initial phase of critical illness (15); (ii) the acute-phase reaction (APR), which has several adaptive functions, including increasing the production of procoagulant factors in preparation for possible tissue damage (16); and (iii) the tissue defense response (TDR) of the target organs [Figure 1; $(11,17)]$. The main effectors of systemic inflammation are the inflammatory cytokines, the acutephase reactants, and the peripheral effectors of the sensory afferent nervous system. The inflammatory cytokines include TNF- $\alpha$, interleukin- $1 \beta$ (IL-1 $\beta$ ), IL-6, chemokines, and other mediators of inflammation. The acute-phase reactants are mostly of hepatic origin and include the C-reactive protein (CRP), 


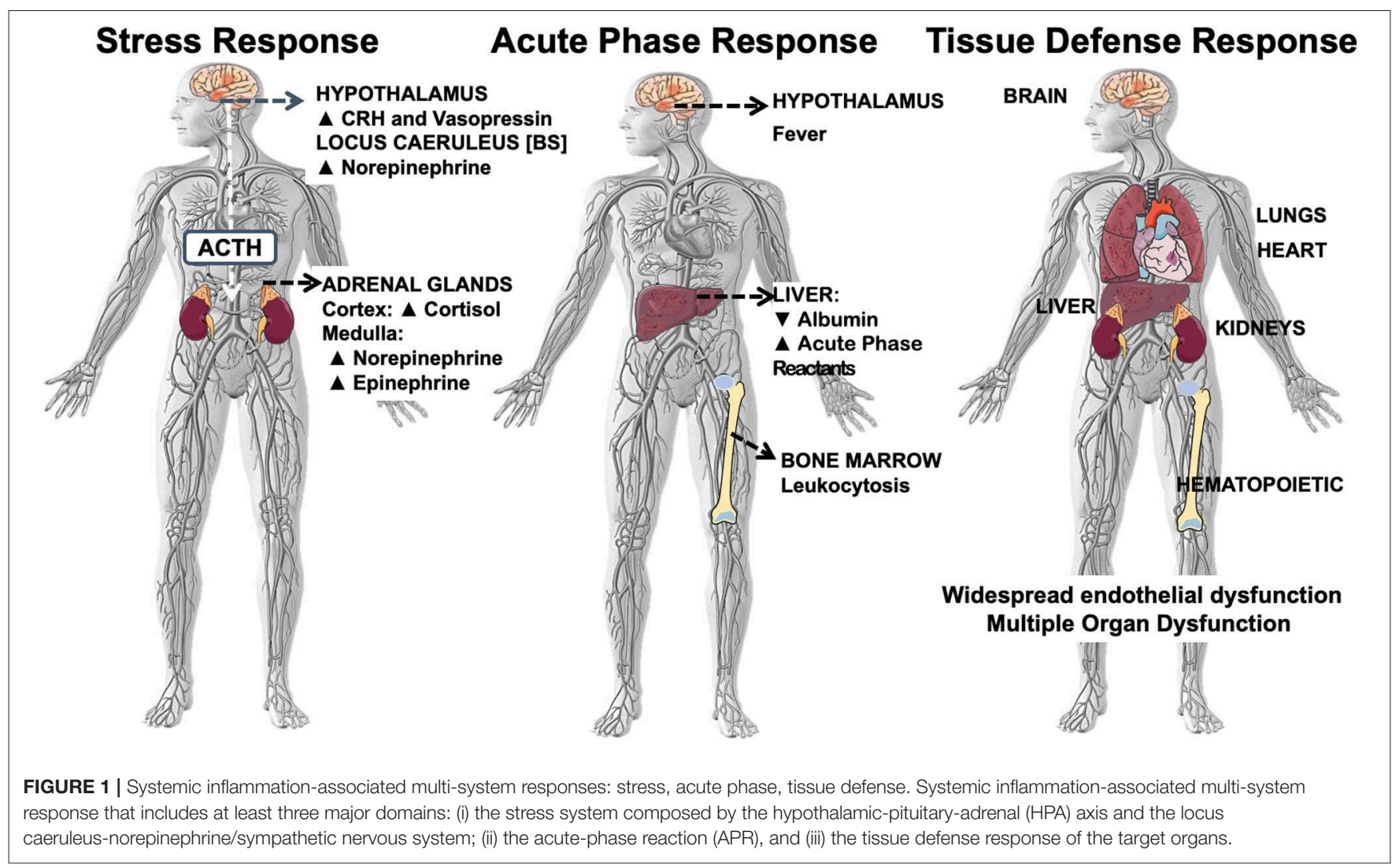

fibrinogen, and plasminogen activator inhibitor-1. During the acute-phase reaction, myelopoiesis is favored at the expense of both lymphopoiesis and hematopoiesis, explaining in part the persistent lymphopenia and anemia of critical illness (18). Substance $\mathrm{P}$ is an example of an effector of the sensory afferent nervous system, while hypothalamic corticotropin releasing hormone $(\mathrm{CRH})$, vasopressin, cortisol, the catecholamines (norepinephrine and epinephrine), and peripheral neuronal CRH represent effectors of the stress system [reviewed in (19)].

The tissue defense response is an integrated network of three simultaneously NF- $\kappa \mathrm{B}$-activated pathways that account for much of the histological, physiological, and laboratory changes observed in vital organs during critical illness (11). These three pathways are those of tissue inflammation, hemostasis, and tissue damage repair: (i) tissue inflammation includes changes in the endothelium, such as loss of the glycocalyx, adhesion/diapedesis of activated neutrophils, endothelial injury, increased porosity with interstitial exudative edema, and loss of vascular tone, and changes in the epithelium, such as loss of integrity and cell apoptosis; (ii) the hemostasis pathway includes platelet activation and aggregation, intravascular clotting with decreased microvascular patency, extra-vascular fibrin deposition, and, lastly, inhibition of fibrinolysis, and (iii) tissue damage repair includes regenerating native parenchymal cells, fibroproliferation and deposition of extracellular matrix, resolution of granulation tissue, and clearance of apoptotic cells and debris (11).
The roles of macrophages and mitochondria in homeostatic corrections is the subject of intense research. Mononuclear phagocytic cells (MPCs), including macrophages and dendritic cells, are widely distributed throughout the tissues of the organism, where they perform essential homeostatic, surveillance, and regenerative tasks. As the neuro-endocrine-immune response progresses, macrophages change phenotype and play an essential role in both innate and adaptive immune responses, in the resolution of inflammation and in the tissue repair and regeneration (discussed further in section Glucocorticoid ReceptorAlpha and Homeostatic Corrections) (20). Mitochondria are targets of GR and critical modulators of homeostatic corrections owing to their critical role in energy production, synthesis of stress-associated steroid hormones, and their capacity to generate signals that promote cellular adaptation (see section Cellular Energetics-Mitochondrial Function) (21).

Systemic homeostatic corrections are driven by elevated levels of circulating inflammatory cytokines, and based on disease progression, can be broadly divided into either adaptive/resolving (regulated systemic inflammation) vs. maladaptive/unresolving (dysregulated systemic inflammation) $(11,14)$. Evidence from the literature on severe sepsis (22-30), acute respiratory distress syndrome (ARDS) (31-35), and trauma $(14,36)$ provides strong support that the degree of NF- $\kappa$ B-driven elevation in inflammatory biomarkers at ICU entry and during 
ICU stay correlates with disease severity and hospital mortality (33, 37-39). In addition to elevated inflammatory markers, critically ill patients have profound activation of the coagulation system (elevated D-dimer levels, prolonged prothrombin time and activated partial thromboplastin time, and reduced levels of the anticoagulant proteins, protein $\mathrm{C}$ and antithrombin) and evidence of endothelial cell activation with disturbed vascular integrity that correlates with disease severity and outcome (see section Endothelium) (40-42). Evidence that hemostasis and inflammation evolved from a single-triggered mechanism can be traced back more than 450 million years ago, based on studies with the horse-shoe crab (Limulus polyphemus) (43).

In hospital survivors, failure to achieve homeostatic correction has a significant negative long-term impact, with experimental work suggesting that it might potentiate the peripheral and brain pro-inflammatory cytokine response to a subsequent inflammatory challenge (44). Independently of age and comorbidities, patients with elevated circulating biomarkers of inflammation and hemostasis at hospital discharge have persistent elevation over time with increased risk for cardiovascular events, re-hospitalizations, and 1-year mortality (41, 45, 46). "Persistent Inflammation, Immunosuppression, and Catabolism Syndrome" (PICS) has been postulated as the underlying pathophysiology of chronic critical illness (CCI) $(18,47)$. About $50 \%$ of sepsis patients have a debilitating condition characterized by a self-perpetuating cycle of persistent low-grade systemic inflammation mimicking chronic stress (elevated cortisol) $(44,48,49)$, glucocorticoid resistance, altered hemostasis $(50,51)$, mitochondrial dysfunction $(52,53)$, and accelerated inflamm-aging $(9,54)$, with increased risk for chronic inflammatory systemic diseases $(7,55)$. The evolutionary trade-off between acutely beneficial and chronically harmful homeostatic corrections was the subject of a recent review (7).

Recently, a critical role was identified for the FKBP5 gene, which encodes the FK506 binding protein 51, a co-chaperone of the GR along heat shock proteins (hsp), including hsp90. The expression of FK506 is stimulated by glucocorticoids and has an inhibitory effect on GR signaling, preventing the nuclear translocation of GR. If short-lived, this negative feedback mechanism to reduce GC signaling may be important to restore HPA axis homeostasis. However, aging and certain stress-related phenotypes are associated with epigenetic upregulation of FKBP5 via decreases in DNA methylation at selected enhancer-related FKBP5 sites, promoting NF-кBrelated peripheral inflammation and chemotaxis, and heightened cardiovascular risk (56). Importantly, translational research indicates that the type of response (regulated or dysregulated) is established early in critical illness $(14,31,57)$, and the previously espoused hypotheses of the second-hit model $(14,22)$, or the two-phase model (compensatory anti-inflammatory response syndrome) are now both considered obsolete $(29,58,59)$.

Based on this pathophysiological construct, we will focus on emerging evidence indicating the central role played by the activated glucocorticoid receptor-alpha $(G R \alpha)$, the master regulator of NF- $\mathrm{\kappa B}$ and homeostatic corrections, in the development and resolution of critical illness. This role is conditioned by its interdependence with functioning mitochondria and by presence of adequate micronutrient reserves. Additionally, we present evidence on how CIRCI, mitochondrial dysfunction/damage, and hypovitaminosis negatively interact to accelerate an anti-homeostatic process of natural selection.

\section{GLUCOCORTICOID RECEPTOR-ALPHA}

The stress system is a complex, sophisticated, and carefully regulated adaptation mechanism that has been shaped by natural selection because it offers a selective advantage (4). All vertebrates express the proopiomelanocortin protein (POMC) that gives rise to adrenocorticotropic hormone (ACTH) which then stimulates the secretion of glucocorticoids. ACTH has long been closely associated with other signaling molecules, such as $\mathrm{CRH}$, vasopressin, biogenic amines (epinephrine and norepinephrine), steroids such as cortisol and aldosterone, cytokines, such as IL-1 $\beta$, and nitric oxide. All of these substances are crucial to adaptation to stressors. It is remarkable that the gene DNA sequences for these molecules have not only been conserved over hundreds of millions of years but also continue to serve closely related adaptive functions (4). This is apparently a result of strong selective forces against mutations that change their sequences and functionality of their products.

Cortisol, the end-product of HPA axis activation, is synthesized from cholesterol in the mitochondria and endoplasmic reticulum of the zona fasciculata of the adrenal cortex. Its synthesis depends entirely on scavenger receptor class B type-I (SR-BI)-mediated cholesteryl ester selective uptake from circulating high-density (HDLs) and low-density (LDLs) lipoproteins (60). In critically ill patients, low serum HDL levels correlate negatively with circulating TNF- $\alpha$ and IL-6 levels $(61,62)$, and positively with mortality $(61,63)$. The combined effects of reduced HDL and SR-BI during systemic inflammation may lead to significant reductions in glucocorticoid production (64). Low HDL (65) and low total cholesterol (66) correlate with inadequate response to ACTH stimulation. In septic shock, prolonged glucocorticoid administration is associated with significant increase in total cholesterol levels within 3 days of treatment (66).

Glucocorticoids are the primary adaptive response mediators, whose signaling system interacts with other cell signaling systems, all essential for maintaining the homeostasis of many of the body's complex functions, including neural, cardiorespiratory, endocrine, metabolic, bioenergetic, and immune responses (67). Within tissues, glucocorticoids are regulated at the pre-receptor level by the isozymes of $11 \beta$ hydroxysteroid dehydrogenase (11ß-HSD), which are located in the endoplasmic reticulum (ER). Glucocorticoids (GCs) bind to the ligand-binding domain of $\mathrm{GR} \alpha$ to produce a biological response. Because of their lipophilic nature, GCs can readily diffuse across cellular membranes to bind to their intracellular receptor and produce a biological/pharmacological response [Figure 2; $(15,68,69)]$. The glucocorticoid receptor is a member of the nuclear receptor (NRs) (70) superfamily that emerged in the vertebrate lineage $\sim 420-440$ million years 


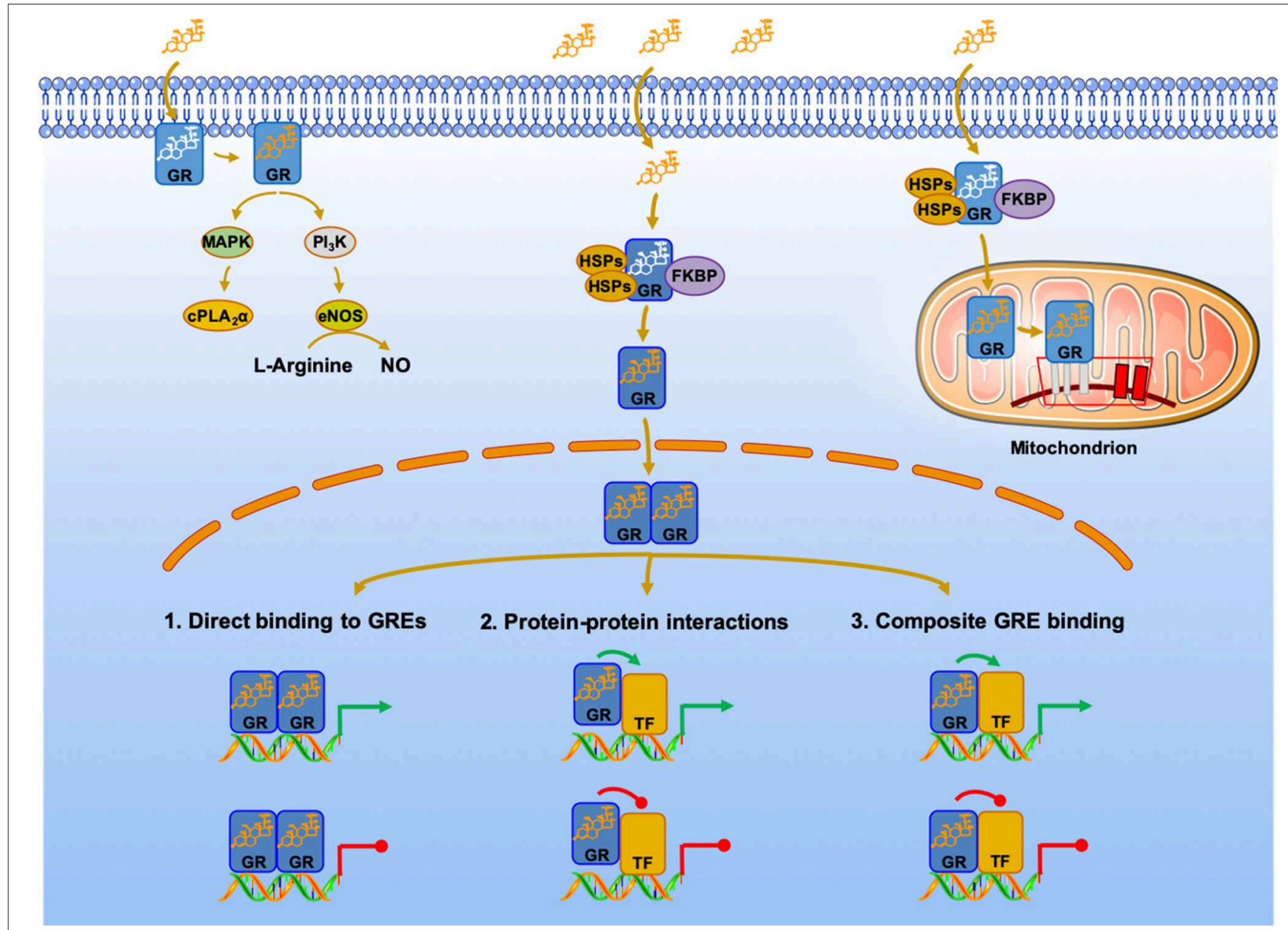

FIGURE 2 | Genomic, non-genomic, and mitochondrial glucocorticoid signaling pathways. Glucocorticoid receptor mechanisms of action. The classic actions of GR $\alpha$ are shown in the middle of the panel. The dormant but ligand-friendly receptor, located in the cytoplasm, is bound to co-chaperon molecules, such as heat-shock proteins and the immunophilin FKBP. Upon binding to the ligand, the activated receptor translocates into the nucleus, where it interacts with GREs and/or other transcription factors, such as NF-кB and AP1, to regulate the activity of glucocorticoid-responsive genes, which represent $\sim 20 \%$ of the human genome. In addition, cell membrane-associated GR $\alpha$ may be activated by the MAPK and PI3K kinases, as shown in the left of the panel. In addition, by as yet unknown mechanism, the $\mathrm{GR} \alpha$ translocates into the mitochondria, where it interacts with the mitochondrial DNA GREs, regulating the activity of mitochondrial genes. See text for additional details CPLA2 $\alpha$, cytosolic phospholipase A2 alpha; eNOS, endothelial nitric oxide synthetase; FKBP, immunophilins; GR, glucocorticoid receptor; HSP, heat shock proteins; MAPK, mitogen-activated protein kinases; NO, nitric oxide; PI3 K, phosphatidylinositol 3-kinase; TF, transcription factor.

ago (similarly to NF- $\mathrm{B}$ ) from sequential duplications of two ancestral genes, those of the estrogen and the glucocorticoid receptors; the latter ultimately evolved into the glucocorticoid and the mineralocorticoid receptors $(67,71)$. Underlying its essential role in formation and regulation of multicellular life, the GR is required to establish the necessary cellular context for maintaining normal uterine biology and fertility through the regulation of uterine-specific actions (72) while GRs are vital for the structural and functional maturation of fetal organs $(73,74)$, affecting almost 4,000 genes (75). In late gestation of mammals, fetal glucocorticoid levels rise dramatically, an essential step for maturation in preparation for life after birth. Also, an association was found between greater maternal affection and warmth in early life and increased expression of glucocorticoid receptor genes in the offspring resulting in long-term health benefits (76).
GRs are present in the cytoplasm (68) and cell membrane (non-genomic effects) (77) in almost all cells of the body and in high concentrations (in neutrophils $\sim 5,000$; in macrophages $\sim 10,000$ ) (78). However, GR levels within the cell are not static, but are tightly controlled by numerous factors and at multiple levels. Notably, 16 variants of the human GR (hGR) have been identified to date with the potential of at least 256 combinations of homo- and hetero-dimers (68). Recent research indicates that the expression of different GR transcriptional and translational isoforms might be a significant factor determining how GCs influence the biological function and activity of specific cells and tissues (75). In contrast to GR $\alpha$, the alternatively transcribed GR $\beta$, which resides primarily in the cell nucleus, does not bind glucocorticoid, but can form homodimers with itself or heterodimers with a GR $\alpha$ subtype, functioning as an antagonist 
of GR $\alpha$. GR $\beta$ homodimers can interact with glucocorticoid response elements (GRE) in the DNA, however their binding does not activate transcription (69). Generally, GR $\beta$ is expressed at very low levels compared to $\mathrm{GR} \alpha$; however, its expression is increased in inflammatory diseases, including critical illness, and this might be associated with decreased sensitivity to GCs and CIRCI (79).

Activation of GR $\alpha$ is not only an essential component of the general adaptation to stress, but also contributes to the maintenance of homeostasis in stress-free conditions (15). The biological response to the GC-GR $\alpha$ complex is affected by cell type, tissue type, and species-specific variations in the repertoire of partnering proteins, ligand concentrations, and other contextual variables $(80,81)$. In stimulated HeLa and neuronal PC12 cells, genome-wide studies identified 8,306 and 2,252 GR genomic binding sites upon treatment with GC, respectively $(12,81)$. Of interest, the availability of these binding sites for interacting with the GC-GR complex depends on the chromatin landscape, which is tissue- and cell type-specific, explaining to some extent, why the GR has a certain effect on one tissue and a totally different effect on another (67). Thus, even though the signaling system is the same, the landscape of the landing site is not. Thus, different cells recognize these signals differently, resulting in a highly context-dependent action by glucocorticoids (67).

After GC binding takes place in the cytoplasm, the activated GC-GR $\alpha$ complex can either (i) bind to several pro-inflammatory transcription factors, or (ii) act as a transcription factor, after translocation into the nucleus and mitochondria (69, 82). Glucocorticoids regulation of mitochondrial transcription via activation of mtGRE was the subject of a recent review (53). In pathway (i), the activated GC-GR $\alpha$ complex interacts directly with activated transcription factors NF- $\kappa \mathrm{B}$ and AP-1, leading to the transcriptional repression of major downstream proinflammatory factors. In pathway (ii), GC-GR $\alpha$ binds to positive (transactivation) or negative (transrepression) specific DNA regions, the glucocorticoid-response elements (GREs) on the nuclear and mitochondrial DNA (83), to directly regulate transcription of target genes. Finally, GC activation of membrane-bound GR rapidly induces the activity of several kinases, such as the mitogen-activated protein kinase (MAPK) or the phosphatidylinositol 3-kinase (PI3K) pathways [Figure 2; (69)]. The non-genomic effects of GCs clearly differ from their well-known genomic effects, with the former responding within several minutes independently of protein synthesis. Genomic studies have shown that the GC-GR $\alpha$ complex regulates more than 3,000 genes in unstimulated peripheral blood mononuclear cells (PBMC) from healthy donors (84), in human pulmonary type II cells (85), and several organs, including the heart $(86)$, liver $(87,88)$, and uterus (72) of unstimulated mice, underscoring its essential role as a master modulator in sustaining life and restoring health. The discordance between the number of regulated genes and the GR sites $(12,81)$ suggests that multiple sites are involved in the regulation of a single gene and/or that binding of a transcription factor is not sufficient to drive gene expression (12).
Control of mRNA turnover is critical in regulating the levels of inflammatory- and immune-mediated gene expression. Recent studies indicate that the GR can mediate GC actions beyond transcriptional gene control; it may actually directly participate, via association with mRNA, in GC-mediated control of cytoplasmic post-transcriptional mechanisms of gene expression (89). In an experimental model (SPRET/Ei mice), increased GR levels and activity were associated with strongly reduced expression levels of cytokines and chemokines in response to LPS-induced lethal inflammation (90).

\section{GLUCOCORTICOID RECEPTOR-ALPHA AND HOMEOSTATIC CORRECTIONS}

In 1984, Munck et al. reviewed the actions of cortisol and proposed that "stress-induced increases in glucocorticoids levels protect, not against the source of stress itself, but rather against the body's normal reactions to stress, preventing those reactions from overshooting and threatening homeostasis (91)." This work and the results of the above genomic studies have led to a reevaluation of glucocorticoids' role in homeostatic corrections. Busillo and Cidlowski (92) recently reviewed the master regulatory role played the activated GC-GR $\alpha$ complex in the three major phases of homeostatic correction involved in disease development and resolution (Figure 3). While distinctions are made between the different states, variable degrees of overlap are likely. First, in the pro-inflammatory phase, GC-GR $\alpha$ prime the innate immune system to remove or neutralize pathogens by: (i) inducing the expression of Tolllike receptor 2, NOD-like receptor pyrin containing 3 (NLRP3) inflammasome, and purinergic receptor P2Y2R; (ii) repressing adaptive immunity (energy conservation); and (iii) cooperating with pro-inflammatory transcription factors NF- $\kappa$ B and activator protein 1 (AP-1) in promoting leukocyte redistribution. The GC induction of NLRP3 sensitizes the cells to extracellular ATP and significantly enhances the ATP-mediated release of proinflammatory molecules, including mature IL- $1 \beta$, TNF- $\alpha$, and IL-6 (93). In addition, inflammatory cytokines, particularly IL6 , nitric oxide, and GCs trigger and modulate the systemic and hepatic acute phase protein response (94). In stimulated HeLa cells, a genome-wide study identified 1,932 gene collectively regulated by the activation of $\mathrm{NF}-\kappa \mathrm{B}$ and $\mathrm{GR} \alpha$, with $43 \%$ of regulated genes responding only when both ligands are added, indicating that $\mathrm{GR} \alpha$ and NF- $\kappa \mathrm{B}$ crosstalk alters signaling pathways that are regulated by each factor separately (12).

During systemic inflammation, peripherally generated TNF$\alpha$, IL-1 $\beta$, IL-6, and other inflammatory cytokines activate the HPA axis at multiple levels to produce GC (95-98). In addition, inflammatory cytokines increase the expression and enzymatic activity of $11 \beta$ hydroxysteroid dehydrogenase type 1 (11ßHSD1), which converts the inactive cortisone to the active cortisol in different cell types, as for example occurs after addition of TNF- $\alpha$ or IL-1 $\beta$ on endothelial (99) or lung epithelial cells (100). Thus, cytokines seem to amplify GC bioavailability (101). Microarray studies have shown that TNF- $\alpha$ and GC synergistically co-regulate 210 genes involved in inflammation 


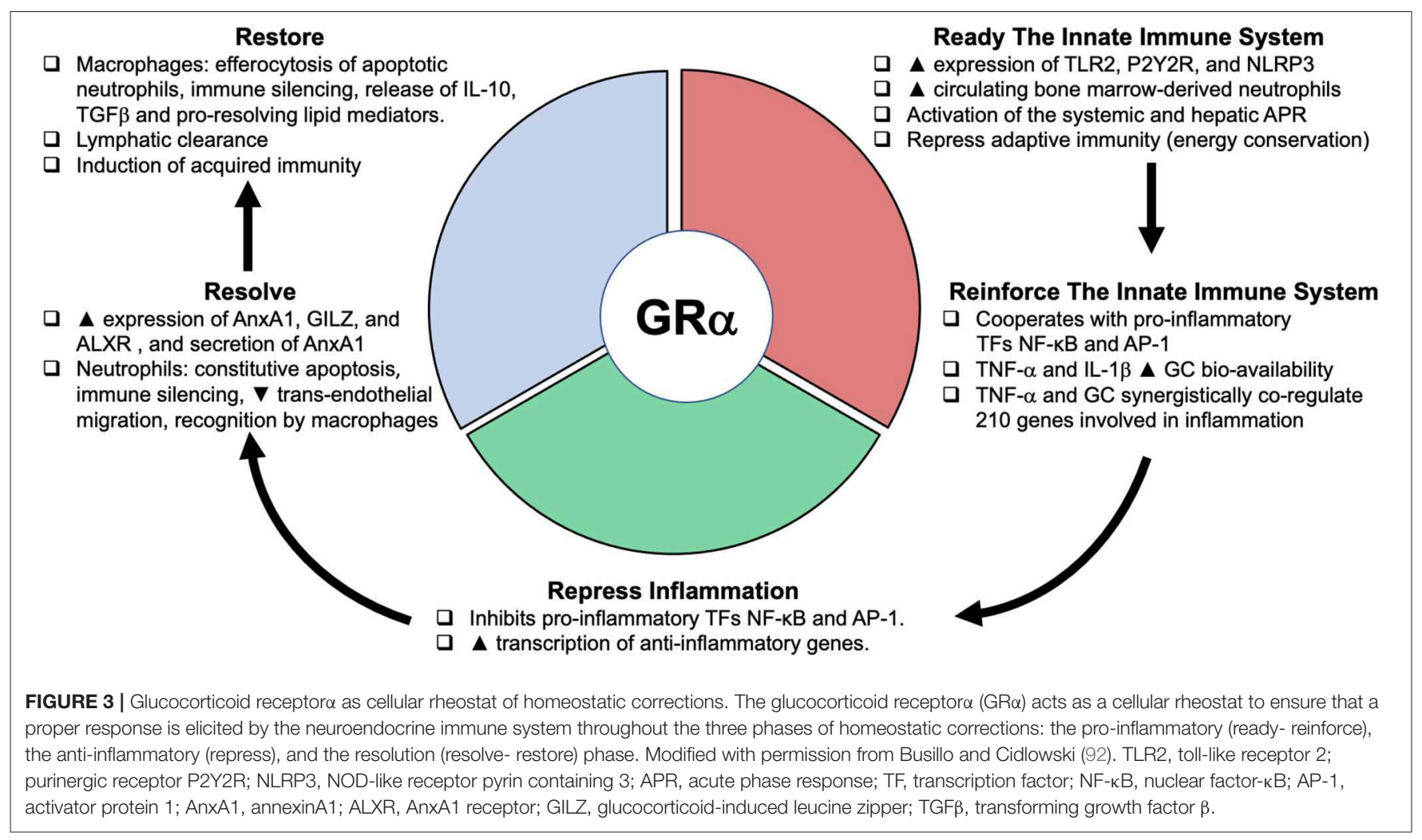

(100). In this context, the synergy between GCs and proinflammatory cytokines is a useful mechanism for rapidly reenforcing initial pro-inflammatory responses. Importantly, GCGR $\alpha$ is necessary to prevent excessive phagocytic cell activation and improve intracellular bacterial killing (102).

In the second phase, when regulated systemic inflammation prevails, GC-GR $\alpha$ exerts classic anti-inflammatory action by (i) inhibiting NF- $\mathrm{KB}, \mathrm{AP}-1$ and other signaling pathways involved in inflammation, and (ii) increasing transcription of anti-inflammatory genes and the $\mathrm{NF}-\kappa \mathrm{B}$ inhibitory protein I $\mathrm{KB}(68,103)$. GC-GR $\alpha$ anti-inflammatory action has been extensively investigated, and we direct the reader to excellent reviews on the $(11,68,101,104-106)$. In upcoming sections, we will review selected mechanisms involved in GC-GR $\alpha$ failure to downregulate systemic inflammation and achieve disease resolution.

The third phase involving disease resolution, i.e., restoration of tissue anatomy/structure and function, is an active and elegantly orchestrated process associated with multiple biochemical pathways, including switching production from pro-inflammatory to pro-resolving mediators (92). As downregulation of systemic and tissue inflammation continues, the activated GC-GR $\alpha$ engages in a host of pro-resolution mechanisms changing, among others, the phenotype of both granulocytes and macrophages. In these immune cells, via genomic mechanisms, GC-GR $\alpha$ increases the expression of AnnexinA1 (AnxA1), AnxA1 receptor (ALXR), and glucocorticoid-induced leucine zipper (GILZ), while via non-genomic mechanisms it increases the secretion of AnxA1
(107-109). The coordinated action of GILZ and AnxA1 is essential to regulating resolution (109). Granulocytes undergo constitutive apoptosis, disabling their potentially injurious secretion responses, i.e., $\mathrm{NF}-\kappa \mathrm{B}$ activation and transcription of inflammatory cytokines, and decreasing trans-endothelial migration leading to their rapid recognition and internalization by macrophages (efferocytosis) (109-112).

Apoptotic cells also serve as resolution cues for macrophages, which, after phagocytosis of apoptotic granulocytes, change their phenotype toward a more resolving/restorative one. The changes in phenotype from M1 (classically) to M2 (alternatively) leads to an orchestrated series of actions leading to successful resolution of inflammation. Interestingly, GCs promote phagocytosis $(112,113)$ and reduce the apoptotic granulocyte ingestion requirements for generation of M2 (114). GC-mediated change to M2 phenotype is associated with (i) immune silencing, where the release of inflammatory mediators and inducible nitric oxide synthase (iNOS) are suppressed (114); (ii) an increased release of the anti-inflammatory mediators IL-10 and TGF $\beta$ and several pro-resolving lipid mediators (114); (iii) protection from apoptosis; (iv) non-phlogistic degradation; (v) production of angiogenic growth factors; (vi) increased macrophage chemokinesis (by upregulation of genes involved in cell mobility) and lymphatic clearance; and (vii) induction of acquired immunity (110, 111, 113-117). GC-mediated Annexin 1-derived peptide $\left(\mathrm{Ac}_{2--26}\right)$ acting through the ALXR receptor has a pivotal role in the clearance of apoptotic cells (118). In models of self-resolving inflammation, various phenotypes of macrophages may coexist. In the later phase of resolution, M2 
macrophages switch to the resolution-promoting macrophage (Mres) phenotype, which display reduced phagocytosis, while producing antifibrotic and antioxidant proteins that limit tissue damage and fibrosis (resolution of granulation tissue) (119). In human monocytes, GCs induce the expression of 133 genes with upregulation of anti-oxidation, migration, phagocytosis, and anti-inflammation with consequent downregulation of adhesion, apoptosis, and oxidation (113). In agreement with microarray data, spontaneous, as well as PMA-induced production of reactive oxygen species, was significantly reduced in GC-treated cells, and GCs promoted survival of an anti-inflammatory monocytic phenotype in inflammatory reactions (113).

\section{GLUCOCORTICOID RECEPTOR ALPHA IN CRITICAL ILLNESS}

Since GR $\alpha$ ultimately controls GC-mediated activity, any condition that affects its concentration, binding affinity, transport to the nucleus, interactions with GREs (nuclear and mitochondrial), cofactor activity (see section Hypovitaminoses), or interaction of other relevant transcription factors (NF-кB, AP-1) and co-regulators, can eventually affect the response of cells to glucocorticoids $(101,120)$. The many different ways GR $\alpha$ function can be negatively influenced by the pro-inflammatory environment of critical illness was the subject of recent reviews $(101,121)$.

Critical illness-related corticosteroid insufficiency is a term used to define the central role played by the HPA-axis and the activated GR $\alpha$ complex in the pathogenesis of dysregulated systemic inflammation in critical illness (17). Three major pathophysiologic events account for the neuroendocrine decompensation observed in CIRCI: (i) multi-level dysregulation of the HPA-axis correlating with circulating inflammatory cytokine levels; (ii) altered cortisol metabolism [reviewed in (122)], and (iii) secondary generalized circulating and tissue specific reduction in GR $\alpha$ number/function with observed multifactorial tissue resistance to endogenous glucocorticoids (17). The role of mitochondrial oxidative stress in reducing GR $\alpha$ number/function is reviewed later (see section Oxidative Stress and CIRCI).

Experimental and clinical studies have demonstrated that critical illness is associated with a significant reduction in GR $\alpha$ density and transcription and an increase in GR $\beta$-mediated dominant negative activity on GR $\alpha$-induced transcription. In a human cell line, activation of NF- $\kappa$ B by TNF- $\alpha$ had a direct doseand time-dependent effect on GR levels with a disproportionate increase in GR $\beta$ over GR $\alpha$ (123). Experimental sepsis is associated with decreased GR $\alpha$ transcription in circulating cells (124), heart (125), lymph node-spleen (124), liver (125127), kidney (127), lung tissue (125-129), and skeletal muscle (125). Moreover, the endothelial GR $\alpha$ is required for protection against sepsis (see section Endothelium) (130). Importantly, the reduction of GR $\alpha$ expression is rapid and persists for at least 5 days (125) while it is associated with increased GR $\beta$ expression in the heart and lung but not liver (125), and increased NF- $\kappa$ B activation (127). Similarly, in experimental ARDS, lung tissue shows a significant reduction in GR $\alpha$ expression $(128,131,132)$ and an increase in GR $\beta$ expression (131), leading to decreased $\mathrm{GR} \alpha$ nuclear translocation (131). In transgenic mice, expression of GR $\alpha$ above wild-type levels leads to increased resistance to LPS-induced endotoxic shock (133).

Clinical studies, including autopsies, in patients with severe sepsis and septic shock have reported a significant reduction in GR $\alpha$ expression in circulating cells (79, 134-137); heart (125), liver and skeletal muscle $(125,138)$, and a significant increase in GR $\beta$ expression in the heart and liver (125). GR $\alpha$ mRNA in neutrophils correlates negatively with plasma IL-6 levels and shows gradual recovery overtime in survivors (135). In another study, neutrophil GR $\alpha$ mRNA levels decreased 4fold by day 4 in the ICU and remained low for 2 weeks (79). In ex vivo experiments with PBMCs exposed to longitudinal plasma samples from patients with ARDS results suggested that insufficient GC-GR $\alpha$-mediated activity at disease onset and over time was a central mechanism for the upregulation of NF- $\kappa$ B activity (Figure 4). Over time, patients with regulated systemic inflammation have a progressive increase in all measured GCGR $\alpha$-mediated activities, including GR $\alpha$ number, binding to NF$\kappa \mathrm{B}$ and to nuclear GRE, as well as increased transcription of I $\kappa \mathrm{B} \alpha$ and IL-10, and a corresponding reduction in NF- $\kappa \mathrm{B}$ nuclear binding, and transcription of TNF- $\alpha$ and IL-1 $\beta$. In contrast, patients with dysregulated systemic inflammation had only a modest longitudinal increase in GC-GR $\alpha$-mediated activities and a progressive increase in NF- $\mathrm{B}$ nuclear binding that was most striking in non-survivors (33). By day 3 of ARDS, no overlap was observed between groups for NF-кB and GC-GR $\alpha$ nuclear binding. In lung tissue obtained by open lung biopsy, histological severity correlated with increased nuclear uptake of $\mathrm{NF}-\kappa \mathrm{B}$ and a lower ratio of GR $\alpha$ : NF-kB uptake (33). A decrease in $\mathrm{GR} \alpha$ expression in critical illness is maladaptive granted that proinflammatory pathways are not properly restrained (124).

Randomized studies $(103,129,132)$ demonstrated in both circulating and tissue cells, that quantitatively adequate and prolonged glucocorticoid supplementation increased GR $\alpha$ number and function, reversing critical illness-associated cellular glucocorticoid resistance. In experimental ARDS, low-dose glucocorticoid treatment restored GR $\alpha$ number and function leading to resolution of pulmonary inflammation (129, 132). Similarly, in an ex vivo ARDS study, prolonged methylprednisolone treatment was associated with upregulation in all measurements of $\mathrm{GR} \alpha$ activity leading to reduction in NF- $\mathrm{B}$ DNA-binding and transcription of inflammatory cytokines [Figure 4; (103)]. Glucocorticoid treatment changes the longitudinal direction of systemic inflammation from dysregulated (NF- $\mathrm{B}$-driven, maladaptive response) to regulated (GR $\alpha$-driven, adaptive response) with significant improvement in indices of alveolar-capillary membrane permeability and markers of inflammation, hemostasis, and tissue repair (11).

\section{ENDOTHELIUM}

The vascular endothelium constitutes the innermost lining of the body's circulatory system and the largest tissue in the body 

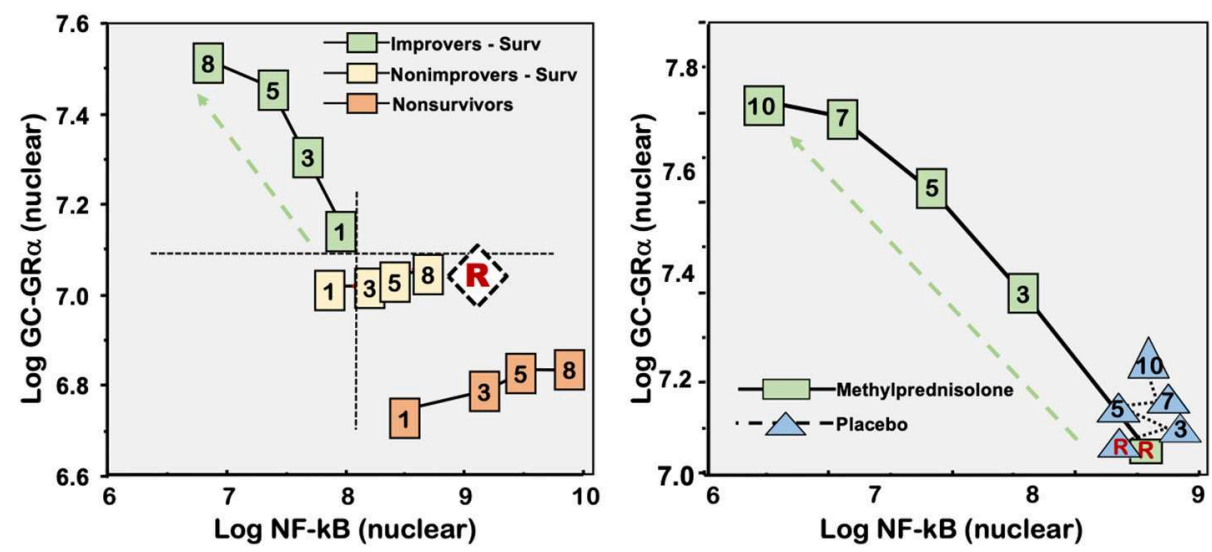

FIGURE 4 | Correlation between mean levels of nuclear NF-kB and nuclear GC-GR $\alpha$ during the natural progression of ARDS, and in response to prolonged glucocorticoid treatment. Mean intracellular changes of nuclear GC-activated GR $\alpha$ and NF-кB observed by exposing PBLs of a healthy volunteer to plasma samples collected longitudinally (days 1, 3, 5, and 8) and after randomization to methylprednisolone treatment [randomization day (R) and post-randomization days 3 , 5, 7, and 10]. The mean values of nuclear NF-кB are plotted against the mean nuclear GC-GR $\alpha$ levels. Improvers had a pre-defined improvement in lung injury score (139) and/or gas exchange component by day 7 . The left panel shows ARDS patients with adaptive and maladaptive responses. In improvers, an inverse relation was observed between these two transcription factors, with the longitudinal direction of the interaction shifting to the left (decreased NF-кB) and upward (increased GC-GR $\alpha$ ). In contrast, in non-improvers NF-кB increased over time while GC-GR $\alpha$ had no significant changes. We define the first interaction as GC-GR $\alpha$-driven, and the second interaction as NF-кB-driven (33). The right panel shows non-improvers-survivors randomized after day 8 of ARDS to methylprednisolone ( $n=11$ ) vs. placebo $(n=6)$. After natural logarithmic transformation and adjustment for repeated measurements, partial correlations among responses to plasma from the methylprednisolone group were $-0.92(p<0.0001)$ both for nuclear NF-кB and nuclear GR $\alpha$. For responses to plasma from the placebo group, no significant relation was found between nuclear NF-kB and nuclear $\mathrm{GR} \alpha(r=0.11 ; p=0.70)$ (103). Reproduced with permission from Meduri et al. (11).

(close to 100,000 miles long) containing $\sim 2.5 \times 10^{12}$ endothelial cells that are typically flat and susceptible to injury, with a thin basement membrane enriched in type IV collagen and laminin (140). The endothelial lining is in continuous contact with circulating cells and soluble proteins, and the capillaries, represent the primary barrier between elements in the blood and the parenchymal cells. The space between two contiguous endothelial cells, known as the endothelial cleft (ETC), acts as an important site of regulation of endothelial (paracellular) permeability (141). Importantly, the vascular endothelium (micro- and macro-circulation) is clothed with a protective barrier, the glycocalyx, which is critical to maintain endothelial homeostasis. The endothelial glycocalyx is a negatively charged, organized mesh of membranous glycoproteins and plasma proteins that include superoxide dismutase, antithrombin III, and cell adhesion molecules, all involved in maintaining the oncotic gradient across the endothelial barrier (141). The intact glycocalyx protects endothelial cells from oxidative stress and prevents the interaction between circulating leukocytes and endothelial adhesion molecules (141). Conformational changes in glycocalyx structure lead to short bursts in the release of endothelial nitric oxide (eNO) (141), inhibiting vascular smooth muscle contraction, platelet aggregation, and leukocyte adhesion, all three processes essential for patency of microcirculation. The blood-brain barrier (BBB), composed of highly specialized endothelial cells with tight junctions that seal paracellular spaces to restrict permeability, serves as a highly restrictive interface between the systemic circulatory system and the brain (142).

Damage to the glycocalyx precedes vascular pathology. Endothelial activation with ubiquitous shedding of the glycocalyx is a major component of critical illnesses and a key pathogenic mechanism in multiple organ dysfunction. The pathways by which sepsis induces injury to the endothelium were recently reviewed (143). The "vasculo-centric view" of critical illness derives from the observation that, despite the remarkable heterogeneity of diseases, the pathobiology of multiple organ dysfunction shares near-stereotypical features that are mostly related to widespread endothelial dysfunction (144). Endothelial dysfunction manifests with a diffuse increase in paracellular permeability, expression of luminal cell adhesion molecules, recruitment of activate leukocytes, altered vasomotor tone, and microvascular thrombosis with decreased capillary density (145). Increasing evidence points to endothelial dysfunction with impairment of the $\mathrm{BBB}$ as a critical component of the pathobiology of delirium during critical illness (146).

Oxidative stress (see section Mitochondrial Cacostatic Load, Oxidative Stress, and Mitochondrial Damage) impairs endothelial function by interfering with eNO synthesis (147) and by participating in the degradation of the glycocalyx (141). After shedding of the glycocalyx, adhesion molecules are released in the blood and can be found in the circulation (35). Microvascular alterations, such as decreased functional capillary density and increased perfusion heterogeneity, are frequently observed in patients with sepsis and contribute to the defect in oxygen extraction by the peripheral organs and tissues of the organism (148).

Endothelial activation may also affect the HPA-axis. The adrenal gland is a highly vascularized organ, with every steroidogenic cell in close vicinity with at least one sinusoid, and a clear positive relation between adrenal blood flow 
and steroidogenesis has been demonstrated (149). In critical illness, disruption of endothelial homeostasis within the adrenal gland can contribute to the HPA-axis dysfunction (150). Hypovitaminosis may also contribute to endothelial dysfunction (see section Hypovitaminoses).

In studies of circulating inflammatory cytokines, there is substantial evidence that in critically ill patients, an increase in circulating markers of endothelial integrity (angiopoietin1; Angpt-1) (145), dysfunction [angiopoietin-2 (Angpt-2), von Willebrand factor (VVF) (150), soluble intercellular adhesion molecule-1 (sICAM-1), (35) vascular endothelial growth factor (VEGF)] $(145,151)$, and cell damage associated with circulating endothelial cells $(152,153)$ correlate with disease severity and mortality. Fittingly, a large study acquiring sublingual measurements of microcirculation in early sepsis, found that mortality strongly correlated with the severity of alterations in the proportion of perfused small vessels, i.e., the functional capillary density (154).

The endothelial GR $\alpha$ is a critical regulator of vascular homeostatic corrections and essential for decreasing the rolling on and adhesion of activated neutrophils to the endothelium (155). In experimental sepsis, elimination of the endothelial $\mathrm{GR} \alpha$ resulted in prolonged activation of endothelial NF- $\kappa \mathrm{B}$, with increased expression of iNOS and inflammatory cytokines, both accounting for hemodynamic collapse and mortality (130). Importantly, the presence of the endothelial GR itself was necessary for GC-mediated suppression of NF-кB and for achieving survival (130). GR $\alpha$ also regulates the tightness of the $\mathrm{BBB}$, inducing expression of the tight junction proteins occludin and claudin-5, and the adherens junction protein vascular endothelium cadherin (VE-Cadherin) (156).

GC-GR $\alpha$ is also strongly involved in vascular development (81). Experimental studies have shown GR-dependent upregulation of multiple mediators involved in endothelial cell homeostasis, such as sphingosine kinase 1 (SphK1) (157), angiopoietin-1 (Angpt-1) (158), serum glucocorticoid kinase-1 (SGK-1) (159, 160), GILZ (161), and eNOS (162-164). In experimental ARDS, upregulation of SphK1, an important regulator of endothelial barrier integrity, was shown to improve alveolo-capillary membrane (ACM) permeability (157). In human brain microvascular endothelial cells (HBMECs), GC treatment was associated with transcriptional activation of Angpt-1 and suppression of VEGF (158). In umbilical vein endothelial cells (HUVECs), upregulation of SGK-1 reduced oxidative stress and improved cell survival and senescence (159); meanwhile, GR-induced GILZ expression (see section Glucocorticoid Receptor-Alpha and Homeostatic Corrections) correlated negatively with vascular inflammation (161). In neuro-vascular tissue, physiological doses of hydrocortisone rapidly activated eNOS via non-genomic mechanisms $(163,164)$.

$\mathrm{GR} \alpha$ is also a critical regulator of myocardial function. In experimental work, the GR-via Kruppel-like Factor 13-was found to play a direct role in the regulation of cardiomyocyte function and protection from hypoxia and DNA damage (86). GR inhibits cells death triggered by ischemia reperfusion, mechanical stress, or TNF $\alpha$ [reviewed in (86)].
The endothelial response to GCs in inflammatory diseases was extensively reviewed covering topics such as inhibition of proinflammatory transcription factors, restoration of endothelial barrier integrity, and induction of protective molecules (140). In experimental sepsis, low-dose glucocorticoid (hydrocortisone or dexamethasone) preserved the endothelial glycocalyx, sustained the vascular barrier and reduced interstitial edema $(165,166)$, and had beneficial effects on mesenteric blood flow and helped with resolution of organ injury (167). GCs play an important role in the control of vascular smooth muscle tone by their permissive effects in potentiating vasoconstrictive responses to catecholamines and other hormones, such as argininevasopressin, through glucocorticoid receptors (168). Finally, they inhibit the expression of inducible nitric oxide synthase and other vasodilatory agents in vascular endothelial cells (169). Additional experimental studies have shown that GR stimulates transcription of the zonula occludens ( $\mathrm{ZO})-1$ tight junction protein, leading to reduced BBB paracellular permeability (142), while it activates eNOS increasing cerebral blood flow (163).

In patients with septic shock $(170,171)$ or ARDS (172, 173), prolonged glucocorticoid (hydrocortisone or methylprednisolone) treatment resulted in the following: (i) increased plasma activated protein C levels (173); (ii) reduction in markers of endothelial injury such as sICAM1 (35); (iii) rapid and consistent improvement in capillary perfusion, independently of the cortisol response to ACTH (170); and (iv) improvement in alveolar-capillary (172) and renal (171) endothelial permeability. In addition, septic shock is associated with vascular dysfunction through NF- $\kappa \mathrm{B}$-mediated downregulation of the endothelial mineralocorticoid receptor (MR) and $\alpha 1$-adrenoceptor, which can be restored with mineralocorticoid (fludrocortisone) treatment (174).

\section{CELLULAR ENERGETICS- MITOCHONDRIAL FUNCTION}

A transforming event in the history of life was the evolution of photosynthetic bacteria, with biochemical pathways that allowed them to capture energy from sunlight and store it in simple sugars, a process known as photosynthesis that generates oxygen as a waste product. As a result, over the course of about one billion years, the earth's atmospheric oxygen increased from almost zero to nearly modern levels (175). The development of an ozone layer in the upper atmosphere to absorb damaging UV radiation from the sun, a derived outcome of increased atmospheric oxygen, permitted organisms to live on land for the first time (175). Some groups of organisms adapted to increased oxygen levels; the most notable adaptation was the evolution of the biochemical pathways of cellular respiration, which use oxygen to extract the energy stored in organic molecules much more efficiently.

About 2 billion years ago, complex life surfaced with two major endosymbiotic (eukaryotic cells ingesting a prokaryote bacterium that resulted in a symbiotic relationship between the engulfing and engulfed cells) events igniting the evolutionary progression to animals and plants $(176,177)$. First, the ancestral 
eukaryotic cell engulfed an aerobic prokaryote bacterium (i.e., capable of using oxygen to produce energy) that eventually evolved into mitochondria (specialized for cellular respiration) populating the cell cytoplasm (modern heterotrophic eukaryote) to afford a selective advantage for survival (178). In the second endosymbiotic event, the early eukaryotic cell engulfed a photosynthetic prokaryote bacterium that evolved into the chloroplast (modern photosynthetic eukaryote).

Central to the integrated actions of immune and neuroendocrine responses $(3,17,179)$ is cellular energetics, involving the mobilization of energy resources from GC-GR $\alpha$ mediated breakdown of glucose (via glycolysis), fatty acids and amino acids for mitochondrial energy production (180). In fact, GCs were originally named by Hans Selye based on their ability to increase blood glucose concentration. Activation of the HPA axis mobilizes these energetic substrates into the circulation within minutes, underscoring the widespread role of GC-GR $\alpha$ in the regulation of systemic metabolism (181).

Mammalian cells, apart from erythrocytes, contain within their cytoplasm hundreds to thousands of mitochondria, the number determined by the energy demand of each cell type. Mitochondria are autonomous and highly dynamic doublemembrane organelles that function as the powerhouses of the cell and utilize $\sim 98 \%$ of total body oxygen consumption. Oxidative phosphorylation (OXPHOS) is the metabolic pathway in the inner membrane of the mitochondria which use enzymes to oxidize ingested calories to produce adenosine triphosphate (ATP) required for normal cell functioning. Ultimately, this conversion provides energy for most cellular processes within the body intracellular reactions (gene transcription and translation, epigenetic modifications), hormonal changes in the endocrine system, structural changes in tissue, and behavioral and cognitive responses] (181), and in theory, determines the limits of an organism adaptive capacity (21).

By virtue of their origins as aerobic bacteria, mitochondria have their DNA, RNA, and protein synthesis systems. The mitochondrial DNA (mtDNA) in our proto-eukaryotic ancestors was significantly larger in genetic complement, but transfer of mtDNA encoded genes to the nucleus has occurred over the 1.52 billion years since the origin of the eukaryotic cell, and today the mammalian mtDNA (inherited from the mother) encodes 13 polypeptides, two rRNAs (12S and $16 \mathrm{~S}$ ) and 22 tRNAs that are essential for OXPHOS and proper cell function (178). Since the mtDNA encodes for only a handful of proteins, mitochondria depend on the cell nucleus and other cellular compartments for most of their proteins and lipids (182). In addition to being the major source of intracellular ATP, mitochondria are deeply involved in signaling pathways, elicited by perturbations in homeostasis, which promote cell adaptation $(183,184)$.

Mitochondria constantly generate reactive oxygen species (ROS) as a by-product of substrate oxidation and oxidative phosphorylation, a physiological process that is normally kept in check by a diversified set of antioxidant defenses (184). The introduction of oxygen to earth's early biosphere stimulated remarkable evolutionary adaptations, and in this context, ROS should be viewed as an essential consequence and driver of evolution and survival over time (185). Reactive oxygen species are required in numerous physiological cell functions, such as cellular signaling systems linked to the transcriptional machinery, maintenance of vascular tone, oxygen sensing, and host defense against pathogens (186). One of the mitochondrial oxidases, the NADPH oxidase of polymorphonuclear leukocytes (primarily neutrophils), is pivotal to the body's defense against pathogenic microorganisms (187).

Mitochondria are involved in a multitude of cellular processes, well-beyond their long-established role as the cell's powerhouse. These include processes such as intracellular calcium homeostasis (buffering of cytosolic calcium), regulation of mitochondrial metabolism, cell migration, production of biomolecules such as amino acids, lipids, hemes, purines, and steroid hormones (see section Mitochondria and HPAAxis Cross-Talk), and activation of cell death pathways (188). Mitochondria trigger cell death pathways by two mechanisms, first via necrosis when ATP levels fall below a certain threshold, and second via apoptosis through the release of mitochondrial cytochrome c into the cytoplasm (189). Mitochondrial integrity is, therefore, essential for the function and survival of cells, and several recent publications have highlighted the critical role played by these organelles in sustaining homeostatic corrections (82, 180-182, 190-192).

\section{MITOCHONDRIAL CACOSTATIC LOAD, OXIDATIVE STRESS, AND MITOCHONDRIAL DAMAGE}

In critical illness, tissue oxygen consumption and total energy expenditure are increased, with intracellular metabolism boosted by up to $200 \%$ compared to the healthy state (193). Cells that represent the innate immune system, like neutrophils, and macrophages, are mainly responsible for the oxidative burst that takes place early in critical illness (194) along with the generation of ROS and nitrogen oxygen species (RNS) that are important for host defenses. In neutrophils of critically ill patients, oxidative activity correlates positively with the degree of intranuclear NF- $\kappa \mathrm{B}$ expression (195). According to the "mitohormesis theory," when present in moderate amounts, ROS and RNS function as intracellular signaling molecules that may improve systemic defense mechanisms by inducing an adaptive response (196). However, when intracellular ROS and RNS concentrations overwhelm antioxidant defenses, cell homeostasis becomes compromised (196). For example, peroxidation of the mitochondrial lipid cardiolipin in the inner mitochondrial membrane leads to dissociation of cytochrome c, reduced production of ATP, and increased generation of ROS (197).

Increased energy and metabolic demands associated with NF- $\kappa$ B-driven dysregulated systemic inflammation, leads to overproduction of ROS and RNS, resulting in significant damage of lipids, proteins, and nucleic acids, both within the mitochondria and in other compartments of the cell [Figure 5; (197)]. Oxidative stress is a predictor of mortality in septic shock patients (198). Glutathione is one of the most important redox buffers of the cells, as it can be found in all cell compartments and acts as a cofactor of several enzymes, 


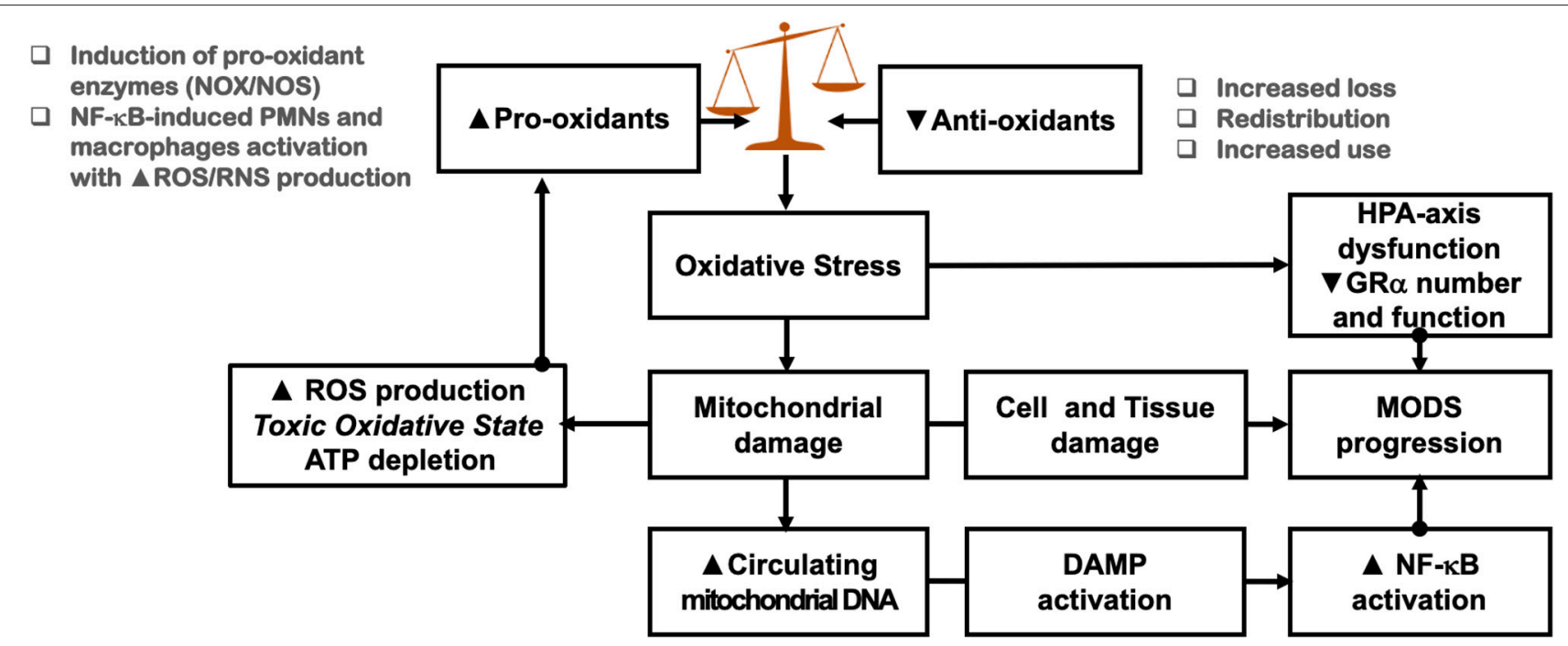

FIGURE 5 | Impact of oxidative stress on homeostatic corrections. See sections Mitochondrial Cacostatic Load, Oxidative Stress, and Mitochondrial Damage, Mitochondria and HPA-Axis Cross-Talk, and Oxidative Stress and CIRCI for explanation. PMN, polymorphonuclear cells; MODS, multiple organ dysfunction syndrome.

helps in DNA repair, scavenges ROS (e.g., hydroxyl radicals, hydrogen peroxide, and lipid peroxides), and generates other antioxidants, such as ascorbic acid (see section Hypovitaminoses) and tocopherols (194). Vitamins D and C upregulate glutathione synthesis and prevent depletion (see section Hypovitaminoses) $(199,200)$.

The multi-level organization of mitochondrial molecular composition, structures, functions, and signaling roles within the cell was recently reviewed (201). In laboratory models of sepsis, mitochondrial respiration is often increased in the early phase of illness, but consistently falls with protracted inflammation [reviewed in (202)]. Many clinical studies implicate mitochondrial dysfunction and bioenergetic failure as an important pathophysiological mechanism underlying dysregulated systemic inflammation-associated multiorgan dysfunction. In a study of skeletal muscle biopsies obtained in septic patients, an association was first reported between nitric oxide overproduction, antioxidant depletion, mitochondrial dysfunction, and decreased ATP concentrations, with progression of multiorgan failure and mortality (203). Human septic cardiomyopathy is accompanied by widespread downregulation of cardiac mitochondrial genes and decrease in the expression of genes that govern cardiac myocyte contractility, analogous to the transcriptional reprogramming that occurs in myocardial hibernation (204). Early sepsis is associated with a reduction in PBMC mitochondrial copy number, and a rise in markers of mitochondrial damage, in a linear relation to proinflammatory cytokine expression (205). The PBMCs of patients with severe vs. less severe pneumonia have increased ROS density, increased DNA damage, and decreased superoxide dismutase (SOD) concentrations (206). Loss of mitochondrial function may lead to compensatory secondary metabolism, glycolysis, to produce ATP as well as lactate (207). A epithelial cell line study demonstrated that this glycolytic switch is promoted by the activation of the redox sensitive phosphoinositide 3-kinase (PI3K) pathway and subsequent inactivation of glycogen synthase kinase-3 $\beta$ (GSK-3 $\beta$ ) resulting in increased production of inflammatory cytokines and reduced sensitivity to glucocorticoids (207).

Decades of laboratory and clinical studies have revealed that dysregulated systemic inflammation, including sepsis, is associated with significant macromolecular damage to mitochondria, particularly in the cells of highly metabolically active tissues, such as the liver, heart, kidneys, brain, and skeletal muscles $(191,208)$. In contrast to nuclear DNA, which is nonimmunogenic, mitochondrial DNA resembles bacterial DNA (see section Cellular Energetics-Mitochondrial Function) and acts as a damage-associated molecular pathogen (DAMP) to activate immune responses through Toll-like receptor 9-mediated activation of NF-кB (209) and the NLRP3 inflammasome (210). Also, in comparison to nuclear DNA, mtDNA is 50 -fold more sensitive to oxidative stress (191), as its close proximity to the electron transport chain and the absence of chromatin proteins makes it an easy target for oxidative damage (197).

As a consequence of increased ROS generation, mtDNA can undergo several qualitative and/or quantitative alterations. Recent studies have found that critically ill patients have decreased cellular mtDNA levels and increased circulating cellfree mtDNA levels $(205,210,211)$. In septic patients, mtDNA depletion in circulating cells (mainly neutrophils) correlates with severity of illness (APACHE II scores) (212), while high TNF- $\alpha$ expression in neutrophil lysates correlates with increased plasma mtDNA levels (205). The exact mechanism of mtDNA delivery into the cytoplasm and then into the systemic circulation is currently unknown (189). In ICU patients with sepsis and ARDS, elevated plasma mtDNA levels $(>3,200$ copies/ $\mu \mathrm{l})$ are associated with dysregulation of phospholipid metabolism (211), and increased mortality (210). 
The cycle of mtDNA damage with loss of function of electron transport enzymes (ATP depletion) and increased ROS generation, a state in which the antioxidant systems are overwhelmed may eventually lead to cell death, a phenomenon known as the "toxic oxidative stress" (213). In critical illness, impaired cell energy metabolism and mitochondrial damage augment systemic inflammation directly via NF- $\mathrm{kB}$ activation and indirectly by multi-level impairment of the HPA axis and GR homeostatic functions (see section Oxidative Stress and CIRCI). Effective homeostatic corrections in the adaptive response during the resolution of critical illness are associated with increased mitochondrial biogenesis, restoration of oxidative metabolism, and mitochondrial content (205). In many studies, restoration of mitochondrial homeostatic functions was observed in association with improved organ recovery and survival [reviewed in (205)]. The association between mitochondrial dysfunction, circulating cell-free mtDNA, muscle wasting, sterile inflammation, and inflamm-aging was recently reviewed (189).

Micronutrient deficiencies may also impair mitochondrial function. In septic patients, the marked early reduction in selenium levels may affect selenium-dependent anti-oxidants glutathione peroxidase and thioredoxin (214). The role of hypovitaminoses on mitochondrial function is reviewed in section Hypovitaminoses.

\section{MITOCHONDRIA AND HPA-AXIS CROSS-TALK}

Abundant mitochondria are one of the most prominent ultrastructural features of the adrenocortical cells (208) in which intracellular steroidogenic cholesterol is ultimately converted to cortisol in a tightly controlled manner (82). The central role of mitochondria in essential physiological processes has rendered these organelles a receiver and integrator hub of multiple regulatory signals (215). Mitochondria participate in the stress response, in part, by sensing levels of glucocorticoids (183). It is now accepted that mitochondria are under GC control because GRs are present in mitochondria, and GREs reside in the mitochondrial genome $(82,192)$. A number of studies in several tissues have observed a cytoplasmic-to-mitochondrion GR translocation or vice versa in response to GC, indicating that mitochondrial GR is dynamically regulated upon exposure to GCs (69). Lee and collaborators have classified five pathways in the functional modulation of the mitochondria by GC-GR (82). In addition to direct mitochondrial GR-mtGRE interactions, mitochondrial gene expression is regulated indirectly by nuclear GR-nuGRE interactions that result in increased transcription of the following: (i) genes encoding OXPHOS and other mitochondrial regulatory functions, (ii) transcription factors for control of nuDNA-encoded mitochondrial proteins, and (iii) several antioxidant mechanisms including uncoupling protein-2 (UCP2) $(69,82,113,192,216,217)$. Of interest, mitochondrial thioredoxin, an antioxidant and anti-apoptotic factor essential for cell viability and vascular homeostasis (218), interacts directly with both the ligand and the DNA-binding domains of GR, keeping the receptor in a reduced, transcriptionally active form $(219,220)$.

Studies have shown that fine-tuning of the response to cellular demands is coordinately regulated by the nucleus and mitochondria, making mitochondrial-nuclear interaction vital to optimal mitochondrial function (82), with GC-GRmediated increased mtDNA gene expression augmenting the total number of mitochondria per cell, and, thus, total cellular energy production capacity (216). Altogether, there is substantial evidence that cross-talk between neuroendocrine control of the stress response and cellular antioxidant systems is essential for mammalian homeostatic regulation (220). Consistent with the cacostatic load model (21), administration of physiological doses of GCs acutely increases mitochondrial membrane potential, calcium buffering capacity, anti-oxidant capacity, and resistance to apoptotic signaling (8), whereas chronic exposure to high doses of GCs suppresses anti-oxidant capacity, decreases mitochondrial membrane potential, and sensitizes cells to apoptosis $(21,187,190)$.

\section{OXIDATIVE STRESS AND CIRCI}

Oxidative stress is accompanied by multi-level impairment of the HPA axis and GR homeostatic functions (Figure 5). In non-survivors of septic shock, marked overexpression of iNOS in hypothalamic parvocellular neurons (PVN) was associated with decreased expression of pituitary $\mathrm{ACTH}$, suggesting that the pro-apoptotic action of iNOS in the PVN may partially account for reduced activity of the HPA axis in sustained septic shock $(221,222)$. In experimental sepsis, adrenal cellular extracts demonstrate a pronounced increase in mRNA for iNOS and inflammatory cytokines that correlate positively with the degree of neutrophil infiltration, adrenal cell apoptosis, and mortality (213).

Changes within the adrenal gland microenvironment may also affect the HPA axis response in critical illness (149), with mitochondrial damage leading to a decreased responsiveness to ACTH (208). Importantly, iNOS expression in adrenal cells diverges at $48 \mathrm{~h}$, with a significant increase observed in nonsurvivors vs. a reduction in survivors (223). In experimental endotoxemia, NF-кB-mediated iNOS release is associated with mitochondrial oxidative stress in adrenocortical cells with inhibition of steroidogenesis and response to ACTH (208).

Oxidative stress has a direct deleterious impact on GRs number and function. Experimental studies involving tissue cultures $(220,224-226)$ and murine models $(227,228)$ have demonstrated that oxidative stress is associated with decreased: (i) GR number (228), (ii) GC binding to GR (220, 224-227), (iii) GC-GR nuclear translocation $(226,229)$, (iv) binding to DNA (224), and (v) inducible gene transcription (220, 225). Nitrosylation, the covalent incorporation of a nitric oxide "nitrosyl" moiety into the critical cysteine(s) residue(s) of the GR is associated with loss of the steroid binding capacity (230).

In human monocytes, genes involved in oxidative functions were significantly overrepresented among GC down-regulated genes, while genes with antioxidant functions were upregulated 
(113). A few studies have evaluated the impact of GC treatment on oxidative stress. In human monocytes, spontaneous, as well as phorbol myristyl acetate (PMA)-induced production of reactive oxygen species, is significantly reduced in GC-treated cells in comparison to controls (113). In murine macrophages, glucocorticoid treatment is associated with rapid (non-genomic) inhibition of superoxide anion production (231). In murine sepsis, GC treatment attenuated renal dysfunction by reducing mitochondrial injury with preservation of cytochrome c oxidase and suppression of pro-apoptotic protein levels (232). In clinical $(233,234)$ and experimental $(162,235)$ randomized trials, participants with severe sepsis receiving GC treatment had, in comparison to controls, a significant reduction in (i) circulating nitric oxide levels $(162,233,235)$, and (ii) spontaneous release of hydrogen peroxide $\left(\mathrm{H}_{2} \mathrm{O}_{2}\right)$ by neutrophils (234).

\section{HYPOVITAMINOSES}

Metabolic homeostasis is substantially disrupted in critical illness, and the degree of a vitamin deficiency can negatively impact health outcomes. Three vitamins, namely thiamine (vitamin B1), ascorbic acid (vitamin C), and vitamin $\mathrm{D}$, are important for the proper function of the GR system and mitochondria, and their reserves are rapidly exhausted in critical illness (236). Vitamins B1, C, and D impact mitochondrial function, while vitamins $\mathrm{C}$ and D also impact GR function. A comprehensive list of suggested mechanisms for the efficacy of thiamine, ascorbic acid, and glucocorticoids in sepsis was recently reviewed (237).

\section{Thiamine}

Thiamine is a water-soluble vitamin, which is passively absorbed in the small intestine. After ingestion, free thiamine is converted to the active form thiamine pyrophosphate (TPP), commonly known as vitamin B1, by thiamine pyrophosphokinase. The majority of TPP in the body is found in erythrocytes and accounts for $\sim 80 \%$ of the body's total storage (238). Thiamine pyrophosphate is a key co-factor for pyruvate dehydrogenase, alpha-ketoglutarate dehydrogenase, transketolase, and branchedchain keto-acid dehydrogenase (238). Pyruvate dehydrogenase is the gatekeeper for entry into the Krebs Cycle, without which pyruvate would be converted to lactate as opposed to acetylcoenzyme A. Alpha-ketoglutarate dehydrogenase is required for completion of the Krebs Cycle once it has begun. Transketolase is a key enzyme for the pentose phosphate pathway and for the production of NADPH with glutathione cycling, an important anti-oxidant pathway (239). There are also other proposed non-cofactor roles of thiamine within the immune system, gene regulation, oxidative stress response, cholinergic activity, chloride channel function, and neurotransmission (238).

The human adult can store around $30 \mathrm{mg}$ of thiamine in muscle tissue, liver and kidneys, however, these stores can become depleted in as little as 18 days after the cessation of thiamine intake (238). A thiamine deficiency syndrome, beriberi, bears a number of similarities to sepsis, including peripheral vasodilation, cardiac dysfunction, and elevated lactate levels (237). In critical illness, the prevalence of thiamine deficiency is $10-20 \%$ upon admission $(198,240)$ and can increase up to $71 \%$ during ICU stay, suggesting rapid depletion of this vitamin (198). Based on limited data, no association was detected between thiamine levels, markers of oxidative stress (198) and mortality $(198,241)$. In one study, a significant negative correlation was reported between thiamine and lactic acid levels in patients with sepsis without liver dysfunction (240). In a pilot randomized controlled trial (RCT) of patients with septic shock $(n=88)$, the administration of thiamine (200 mg twice a day for 7 days) reduced lactate levels and improved mortality over time in a predefined subgroup of patients with thiamine deficiency (35\% of cohort) (239). In a retrospective, single-center, matched cohort study, administration of thiamine within $24 \mathrm{~h}$ of septic shock ( $n=123)$ was associated with improved likelihood of lactate clearance and a reduction in 28-day mortality (242). Despite some promising results, there is insufficient evidence to support or reject thiamine supplementation as a monotherapy in critically ill patients (238).

\section{Vitamin D}

Vitamin D is an ancient molecule that functions as both a nutrient and a hormone with metabolic and immunomodulatory properties; it regulates over 1,000 genes of the human genome $(243,244)$. The vitamin D receptor (VDR) is a member of the nuclear receptor gene family and is expressed in virtually all nucleated cells. Decreased serum levels of vitamin D have been associated with several autoimmune inflammatory diseases. Genome-and transcriptome-wide studies indicate that vitamin $\mathrm{D}$ signaling modulates many inflammatory responses on several levels (245), including interference with NF- $\kappa$ B, via upregulation of $\mathrm{I} \kappa \mathrm{B}$ expression (246). In addition, the ability of vitamin D to inhibit metabolic stress and energy expenditure in a cell microenvironment suggests that this pleiotropic hormone has a broad task as a pro-survival agent (244).

A growing body of scientific and medical literature supports the important anti-inflammatory functions of vitamin $\mathrm{D}$ in health and disease, including the enhancement of GC-mediated anti-inflammatory actions (247). The anti-inflammatory effect of vitamin D was consistently observed in studies of cell lines and human PBMCs, and was the subject of a comprehensive review (248). PBMCs activated with TLR ligands after incubation with $1,25(\mathrm{OH}) \mathrm{D} 3$ showed decreased release of TNF- $\alpha$ and IL-1 $\beta$ and increased anti-bacterial activity (249). In PBMCs, physiologic levels of vitamin $\mathrm{D}$ reduce inflammatory activities, by upregulating GC-mediated mitogen activated protein kinase (MAPK; see section Glucocorticoid Receptor-Alpha) phosphatase-1 (MKP-1) (250) to down-regulate p38 MAPKmediated inflammatory gene expression (including TNF- $\alpha$, IL-1 $\beta$, IL-6, and IL-8) (251). In LPS-activated PBMCs (247) and PBMCs from patients with asthma (252), vitamin D enhanced dexamethasone-induced expression of MKP-1 (247), and this synergism was dependent on vitamin D-induced GM-CSF release (247). One study suggested that the interaction between vitamin $\mathrm{D}$, glucocorticoids and their cognate receptors is related to the duration of exposure to vitamin D (253).

Beside this indirect modulation of signaling cascades, vitamin $\mathrm{D}$ and its receptor complex VDR/RXR can interact directly 
with the GC receptor and other transcription factors (245). Of interest, Vitamin D has a high affinity binding for the GR (254), and was recently shown to increase, in a dosedependent manner, GR concentration in T cells (255). Based on its pleiotropic functions, vitamin D is considered a "master tuner" in shifting homeostatic balance from a pro-inflammatory to a pro-resolving status (244). Several studies demonstrated a dose-dependent response of vitamin $\mathrm{D}$ with respect to reducing inflammation, with $1 \mathrm{nM}$ and $10 \mathrm{nM}$ concentrations causing the greatest effects (248). One study showed that serum $25(\mathrm{OH}) \mathrm{D}$ levels as high as $120 \mathrm{nmol} / \mathrm{l}$ may be necessary for optimal immune function (256). A small study in healthy patients with hypovitaminosis $\mathrm{D}$ reported that significant antiinflammatory benefits of vitamin D supplementation were only seen by achieving serum 25(OH)D levels greater than 100 nmol/l (256).

The mitochondria also appear to be a direct target of the vitamin D endocrine system, and the two most important enzymes responsible for activation or inactivation of 25(OH)D, namely CYP27B1 (1 $\alpha$-hydroxylase) and CYP24A1 (24-hydroxylase), are located in the mitochondria (257). In U937 monocytes, 1,25 (OH)2 vitamin D upregulates glutamate cysteine ligase (GCLC) and glutathione reductase (GR), resulting in an increase of cellular glutathione formation, and decreased ROS and IL-8 secretion (258). Two recent studies have evaluated the impact of vitamin $\mathrm{D}$ on skeletal muscle mitochondrial function. Primary human skeletal muscle cells treated with $1,25(\mathrm{OH}) \mathrm{D} 3$ vs. vehicle demonstrated marked effects on mitochondrial number, morphology, physiology, and expression of key mitochondrial proteins, resulting in increased ATP production (259). In vitamin D-deficient symptomatic patients, Vitamin D supplementation was found, using phosphorus31 magnetic resonance spectroscopy, to augment muscle mitochondrial maximal oxidative phosphorylation after exercise and improved symptoms of fatigue (260). Treatment of skeletal muscle with vitamin $\mathrm{D}$ is associated with a change in expression of $\sim 83$ nuclear mRNAs encoding proteins known to localize in mitochondria (259).

Hypovitaminosis D is common in critical illness, despite parallel elevations of PTH (249) with one small study reporting a progressive drop in vitamin $\mathrm{D}$ levels in the first week of illness (261), while a low 25(OH)D3 status was significantly associated with all-cause and sepsis mortality (236). In early critical illness, vitamin D status is associated with a differential metabolic profile. Glutathione and glutamate metabolism, which play principal roles in redox regulation and immunomodulation, respectively, were significantly upregulated by vitamin D (199). However, evidence of a mortality benefit of vitamin $\mathrm{D}$ as monotherapy still remains uncertain $(262,263)$. A recent large RCT investigated a single dose of 540,000 international units of vitamin $\mathrm{D}_{3}$ in critically ill patients with $1,25(\mathrm{OH}) \mathrm{D} 3$ levels $<20 \mathrm{ng} / \mathrm{ml}$ (264). By day 3, the treated group achieved a level of 25 -hydroxyvitamin D of $46.9 \pm 23.2 \mathrm{ng} / \mathrm{ml}$; measurements of systemic inflammation were not reported. Treatment was not associated with improvement in mortality or secondary variables (264).

\section{Vitamin C}

Ascorbic acid (vitamin C) is a potent water-soluble antioxidant and an enzymatic cofactor that plays a key role in neuroendocrine and immune homeostatic corrections (265). Most vertebrates can synthesize ascorbic acid from glucose-6-phospate in the liver, with synthesis increasing during stress. In humans and other primates, however, ascorbic acid cannot be synthesized and has to be obtained through the diet. This is the result of a random mutation in the enzyme that catalyzes the final step of ascorbic acid biosynthesis in the common ancestor of the teleost fish some 200 million years ago $(266,267)$. To date, there is no satisfactory evolutionary explanation for this apparent random loss of ascorbic acid synthetic ability. Individuals from species which have lost the ability to make their own ascorbic acid were not selected against, as long as their diet contained sufficient quantities of vitamin C (266).

Ascorbic acid is actively transported into all cells of the body (except erythrocytes) by the sodium vitamin $\mathrm{C}$ transporter-2 (mSVCT2). Ascorbic acid is differentially accumulated by most tissues and body fluids. Studies using radiolabeled ascorbic acid predict that body stores in healthy humans are about $1,500 \mathrm{mg}$; scurvy is thought to occur when this level falls below $300 \mathrm{mg}$, with plasma ascorbic acid concentrations $<11.3 \mu \mathrm{M}$ (268). Importantly, the highest concentrations $(\mu \mathrm{M})$ of ascorbic acid are found in critical organs involved in homeostatic corrections, such as the pituitary gland $(2,300-2,800)$, the adrenals $(1,700-$ 2,300), the brain norepinephrine-synthesizing nuclei (800900), and liver (600-900) (268). This vitamin-sequestering may represent an evolutionary protective or "safety" function.

Ascorbic acid is a key cellular antioxidant. As such, ascorbic acid is an electron donor that directly scavenges for free radicals, and inhibits the generation of new free radicals through its suppressive effects on the NADPH oxidase (NOX) pathway (237). Ascorbic acid also prevents the depletion of other circulatory antioxidants, such as lipid-soluble vitamin $\mathrm{E}$ and glutathione, although this is not the case in reverse (200). The anti-oxidant effects of ascorbic acid result in reduced endothelial permeability, improved microvascular and macrovascular function, attenuated cellular apoptosis in pathological states, and improved GR function (237).

Ascorbic acid is maintained at high levels in mature circulating leukocytes ( $\mu \mathrm{M}$ amounts in lymphocytes $\sim 3,800$; monocytes $\sim 3,100$, and neutrophils $\sim 1,400$ ) (268), suggesting an important role in many aspects of the immune response. In leukocytes, ascorbic acid content responds to variations in plasma ascorbate availability (269). Following activation, immune cells undergo dramatic metabolic reprogramming with increased aerobic glycolytic activity and fatty acid oxidation (Warburg effect) under the regulation of hypoxia-inducible factors (HIFs) (270). The result of this change is to rapidly provide ATP and metabolic intermediates for the biosynthesis of immune and inflammatory mediators. Importantly, the hydroxylase enzymes that regulate the actions of the HIFs require ascorbate for optimal activity (269). The immune-enhancing properties of ascorbic acid regulation of HIFs include increased neutrophil and macrophage bacterial killing and phagocytic capacity $(269,271)$. In addition, 
ascorbic acid plays an important role in protecting host cells from the excessive oxidative stress caused by infections (265).

Ascorbic acid plays a crucial role in HPA axis function (Figure 6). In adrenocortical cells ascorbic acid is sequestered in two pools, one of which can be depleted by ACTH. In response to inflammatory cytokine-mediated ACTH release from the anterior pituitary gland, the adrenal gland rapidly secretes ascorbic acid in amounts that are sufficient to increase, by several fold, plasma ascorbic acid concentrations in the adrenal vein, without increasing systemic levels (268). More than 80 years ago Hans Selye, the pioneer of stress research, reported that the adrenal glands not only contain some of the highest concentrations of ascorbic acid in the human body, but they also employ this vitamin to synthesize cortisol in the adrenal cells (272). Today, in vitro and in vivo studies have shown that ascorbic acid is an essential cofactor required in both adrenal mitochondrial steroidogenesis and catecholamine biosynthesis (272). The level of ascorbate in the adrenals might affect their capacity to convert cholesterol into pregnenolone, the precursor from which nearly all steroid hormones, including cortisol, are made (273). Additionally, ascorbic acid, as an antioxidant, has a positive impact on GR functions (see section Oxidative Stress and CIRCI).

Oxidative conditions modulate negatively ligand-dependent and independent nuclear import of the GR, affecting GC-GR $\alpha$ DNA binding, and inducible gene expression $(225,229)$, while a phosphodiester compound of ascorbic acid reverses oxidation of the GR, thereby, restoring the cellular glucocorticoidresponsiveness in oxidant conditions (225). Finally, the cellular uptake of ascorbic acid, mediated by mSVCT2, is downregulated during inflammatory conditions. In a time and concentrationdependent manner, GCs increase the expression of mSVCT2, facilitating the uptake of vitamin C into cells (274), providing the rationale for combination treatment using GCs and ascorbic acid (275). Interestingly, there is a strong inverse correlation between the ability of an animal to endogenously produce vitamin $\mathrm{C}$ and the induction of a cortisol response when stressed (276).

In human cell lines and primary endothelial cells (ECV304 and HUVEC), ascorbic acid inhibits TNF $\alpha$ and IL-1 $\beta$ induced activation of NF- $\kappa \mathrm{B}$, in a dose-dependent manner, by inhibiting phosphorylation and degradation of I $\mathrm{I} \mathrm{B} \alpha$ $(277,278)$, independently of its antioxidant properties (277). Preclinical studies show that high-dose vitamin $\mathrm{C}$ can prevent or restore microcirculatory flow impairment, reinstate vascular responsiveness to vasoconstrictors, and preserve the endothelial barrier (200). Both ascorbic acid (279) and the GR (see section Endothelium) (130) are essential for endothelial cell homeostasis, and the combination of glucocorticoids with ascorbic acid is superior to either one on its own in protecting vascular endothelium that is critical to allow recovery (280).

Many studies have demonstrated that vitamin $\mathrm{C}$ levels are rapidly depleted in critically ill patients, with about $40 \%$ of the septic patients having reduced serum levels, similar to those seen at scurvy diagnosis $(<11.3 \mathrm{u} / \mathrm{mol} / \mathrm{l})(281,282)$. As intracellular ascorbate concentrations in mononuclear leukocytes and in granulocytes are, respectively, 80 and 25 times higher than in plasma, a high production and turnover of these cells may also contribute to its depletion (200). Low plasma concentrations of vitamin $\mathrm{C}$ are associated with more severe organ failure and increased risk of mortality (282). Similar to thiamine, ascorbic acid deficiency syndrome (scurvy) bears a number of similarities to sepsis, including coagulation abnormalities, and breakdown of the endothelial wall (282).

In a phase I safety trial, intravenous ascorbic acid infusion was safe, well-tolerated, and associated with improvement in multiple organ dysfunction and decreased biomarkers of inflammation and endothelial injury (281). Additionally, a small RCT investigating high dose ascorbic acid administration in patients with septic shock reported a reduction in 28-day mortality (283), while a larger trial in patients with sepsis-associated ARDS reported a significant reduction in 28-day all-cause mortality

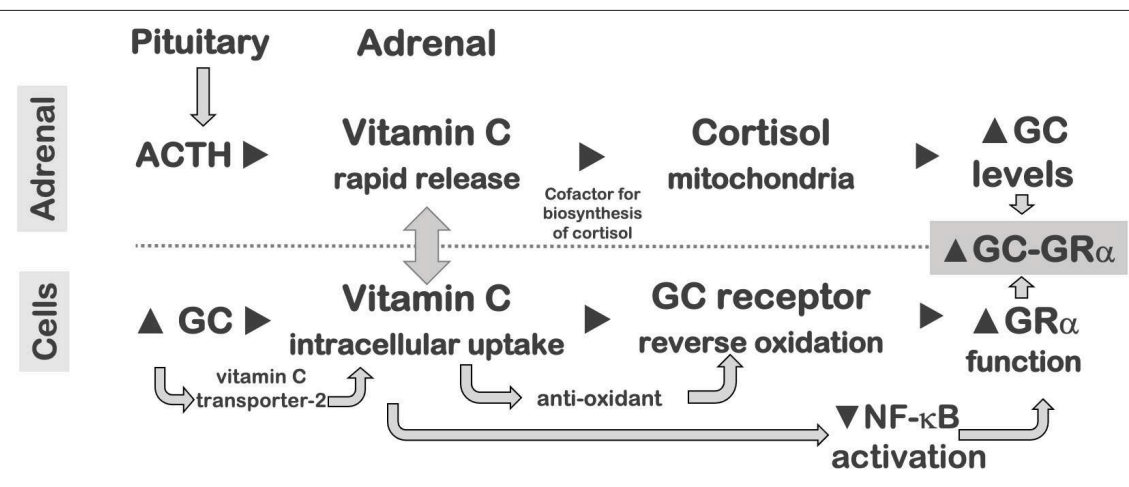

FIGURE 6 | Impact of vitamin C on activated GR $\alpha$ activity. (Top) Adrenal: The adrenal and pituitary glands have very high concentrations of ascorbic acid (vitamin C). In response to ACTH release from the corticotrophs of the anterior pituitary gland, the adrenal gland rapidly secretes ascorbic acid, an essential cofactor required for adrenal steroidogenesis in mitochondria, contributing to increased glucocorticoids synthesis. (Bottom) Cells: glucocorticoids, in a time- and concentration-dependent manner, increase the expression of mSVCT2, facilitating the uptake of ascorbic acid into the cell. Ascorbic acid reverses oxidation of the GR, restoring cellular glucocorticoid-responsiveness in oxidant conditions. In addition, ascorbic acid inhibits TNF $\alpha$ - and IL-1 $\beta$-induced activation of NF-KB in a dose-dependent manner by inhibiting phosphorylation and degradation of $\mathrm{lkB} \alpha$. These combined actions result in increased glucocorticoid availability and GC-GR $\alpha$ activation and improved homeostatic corrections. 
(secondary outcome) (284). The rationale for glucocorticoid treatment in association with high dose ascorbic acid was the subject of recent reviews $(237,267)$. The promising findings of a recent retrospective study in patients with severe sepsis and septic shock has spurred considerable interest in the subject (275). Randomized data to confirm or refute the observational evidence for the drug combination are needed, and several clinical trials are ongoing or planned in the near future (237).

\section{CONCLUSIONS AND IMPLICATIONS FOR GLUCOCORTICOID TREATMENT}

In critical illness, homeostatic corrections, the culmination of millions of years of evolution, are modulated by the activated GC-GR $\alpha$ and associated with an enormous bioenergetic and metabolic cost. We have reviewed how CIRCI, mitochondrial dysfunction/damage, and hypovitaminosis collectively interact to accelerate an anti-homeostatic active process of natural selection. Importantly, the allostatic overload imposed by homeostatic corrections impacts negatively on both acute and long-term morbidity and mortality, while the bioenergetic and metabolic reserves to support homeostatic corrections are time limited. For these reasons it is prudent to implement early interventions designed to achieve the following: (i) reinforce innate immunity, (ii) inhibit further systemic tissue damage, (iii) limit the metabolic and bioenergetic cacostatic overload imposed during vital organ support, (iv) accelerate disease resolution, and (v) prevent persistent-chronic low-grade systemic inflammation (285). This approach is supported by experimental (286) and clinical studies in patients with septic shock or ARDS (287-290).

The actions of the activated GR $\alpha$ cannot be categorized as merely anti-inflammatory, as it is now clear that insufficient intracellular $\mathrm{GR} \alpha$ regulatory action and not relative adrenal insufficiency is the primary driver of CIRCI (17). Therefore, glucocorticoid treatment should not be viewed exclusively as anti-inflammatory or as a hormone replacement for relative adrenal insufficiency. It also is equally relevant that one should recall that full biological resolution lags weeks behind clinical resolution of an acute illness, making the clinical criteria that we frequently employ to guide duration of treatment, an inadequate reference point (291). For these reasons, glucocorticoid treatment, and other co-interventions should be directed at supporting the activated GR $\alpha$ regulatory function throughout all phases of homeostatic corrections, and not limited to the acute phase of organ support.

Randomized studies provide evidence that prolonged glucocorticoid administration is associated with increased $\mathrm{GR} \alpha$ number and function and decreased oxidative stress (see sections Glucocorticoid Receptor Alpha in Critical Illness and Mitochondria and HPA-Axis Cross-Talk). Additionally, the activated GR $\alpha$ interdependence with functional mitochondria and three vitamin reserves provides a rationale for cointerventions that include rapid replacement of vitamins B1, C, and D. Recent evidence generated from a retrospective before-after clinical study in patients with severe sepsis has generated momentum for increased research in this field (275), with ongoing confirmatory randomized trials in progress (282).

Additional co-intervention with critical hormones and mediators involved in homeostatic corrections are also necessary, such as fludrocortisone $(174,292,293)$ or vasopressin (294296 ) in patients with septic shock. Fludrocortisone is a mineralocorticoid and glucocorticoid receptor agonist that binds to cytoplasmic receptors, activates their translocation into the nucleus and subsequently initiates the transcription of mineralocorticoid- and glucocorticoid-responsive genes (297). The inclusion or exclusion of fludrocortisone, as a cointervention with hydrocortisone, may partly explain the differences reported in outcomes of some RCTs (see explanation for Figure 7 below) $(292,298)$. Other potential co-interventions directed at increasing glucocorticoid receptor expression, such as statins (299), melatonin (300), beta-blockers (301), calcium channel blockers (301), or directed at improving mitochondrial function $(194,302,303)$ have not been investigated in association with glucocorticoid treatment in acute illness or alone in chronic critical illness.

Present understanding of the activated GC-GR $\alpha$ 's role in immunomodulation and disease resolution should be taken into account when re-evaluating how to administer glucocorticoid treatment and in monitoring treatment responses. There are many variables to consider, including the type of GC to be used, timing, dosage, mode of delivery, co-interventions, duration, and tapering. Over the last 40 years, multiple randomized trials investigating GC treatment in critical illness have clearly shown that the design of a treatment protocol has a profound impact on treatment response and outcome $(304,305)$. The CONSORT (306) and GRADE (307) systems, while useful in evaluating the quality of a randomized trial, unfortunately lack a position on two fundamental elements of a trial design, namely the disease pathophysiology and the pharmacological principles applicable to the investigated drug. Unfortunately, lack of these specific reference points has generated misinterpretation of the literature, fueling a non-sensical controversy that clearly is not serving the patient (308).

Based on this updated pathophysiological understanding, we offer a few observations and make recommendations for future research. Early initiation of treatment, before homeostatic corrections reach exhaustion, is critical and should be directed at approaching maximal saturation of the glucocorticoid receptor ( $\sim 100 \mathrm{mg}$ of methylprednisolone equivalent) (309). An adequate initial loading bolus is necessary to achieve prompt elevation in plasma levels and to assure higher $\mathrm{GR} \alpha$ saturation in the cytoplasm and on the cell membrane for genomic and non-genomic actions, respectively. In human monocytic cells activated with graded concentrations of LPS and then exposed to graded concentrations of methylprednisolone (Figure 7), reduction in inflammatory cytokine transcription was initially modest, then-after reaching an inflection point-followed by a rapid reduction, likely related to achieving maximal drug receptor saturation and adequate time for a measurable effect (102). To achieve optimal results, the initial loading bolus should be followed by an infusion (daily dose over $24 \mathrm{~h}$ ) to rapidly achieve a steady state. In patients with septic shock, 


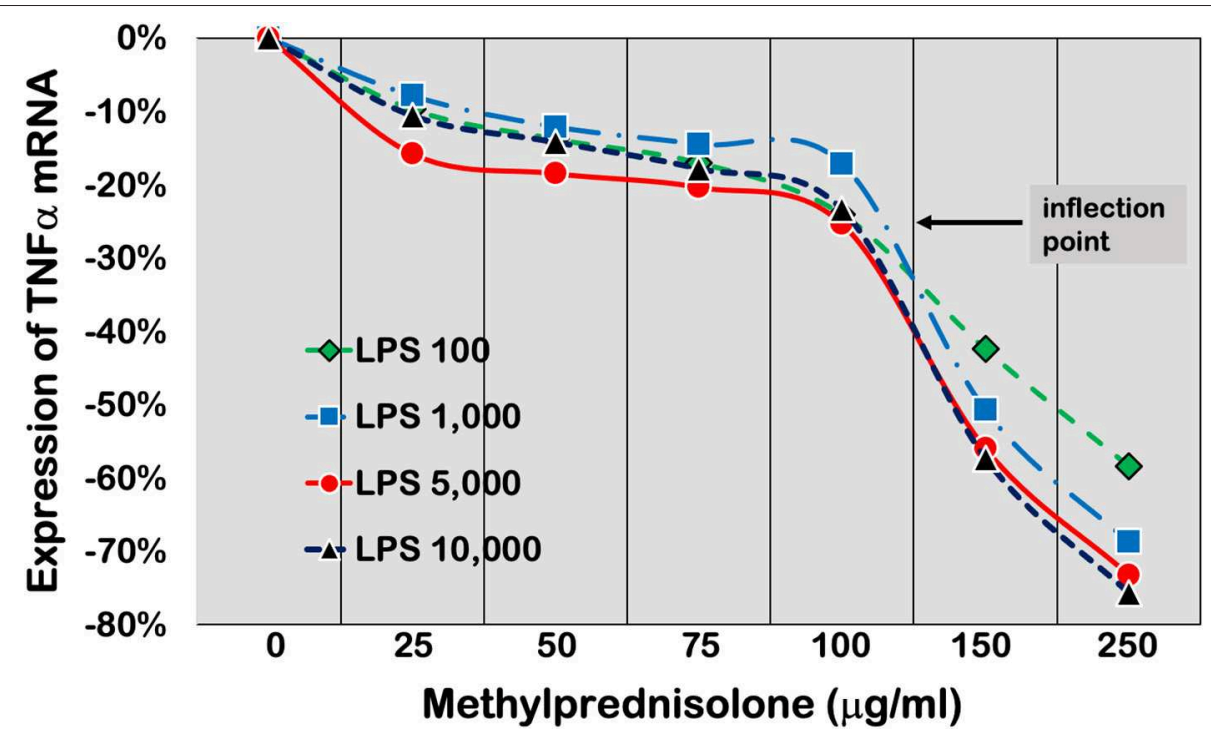

FIGURE 7 | Regression of concentration of methylprednisolone on steady-state mRNA levels of TNF- $\alpha$ in U937 cells primed with graded concentrations of lipopolysaccharide (LPS). In experimental simulation of severe inflammation, human monocytic cells (U937 cells) were activated with graded concentrations of LPS $(100 \mathrm{ng} / \mathrm{ml}, 1.0 \mu \mathrm{g} / \mathrm{ml}, 5.0 \mu \mathrm{g} / \mathrm{ml}$, or $10.0 \mu \mathrm{g} / \mathrm{ml})$ for $6 \mathrm{~h}$ followed by measurement of the expression of inflammatory cytokines [TNF- $\alpha$ (shown), IL-1 $\beta$, and IL-6]. Graded concentrations of LPS were followed by progressively higher inflammatory cytokine transcription (for TNF- $\alpha$ : 185, 318, 481, and 566, respectively). These cells were then exposed to graded concentrations of methylprednisolone $[(\mu \mathrm{g} / \mathrm{ml}): 50,100,150,200,250]$ for $6 \mathrm{~h}$ followed by repeated measurement of inflammatory cytokine expression (see below). The steady state mRNA levels of TNF- $\alpha$, IL-1 $\beta$, or IL- 6 in LPS-activated cells were reduced by treatment with methylprednisolone in a concentration-dependent manner. The effective dose of methylprednisolone was $175 \mathrm{mg}$, a value that appeared to be independent of the priming level of LPS and type of mRNA measured (102). Modified with permission from Meduri et al. (102).

hydrocortisone administered as an infusion vs. an intermittent bolus was associated with more rapid resolution of shock (310), and fewer hyperglycemic episodes $(311,312)$.

In general, synthetic glucocorticoids are more potent immunoregulators than is cortisol, because they are not subject to endogenous clearance and inhibitors of cortisol activity, including $11 \beta \mathrm{HSD}$ inactivation. Moreover, synthetic glucocorticoids bind the glucocorticoid receptors with higher affinity and remain longer in the cell nucleus, while they bind to mineralocorticoid receptors with lower affinity than do endogenous glucocorticoids, thereby minimizing mineralocorticoid-related side effects (313). Pharmacokinetics and pharmacodynamics of systemically administered glucocorticoids are reviewed in reference (314). Hydrocortisone and methylprednisolone are the two glucocorticoids most often investigated in critical care RCTs (315). In the past, different exogenous glucocorticoids were thought to be qualitatively indistinguishable from each other because they act via the same glucocorticoid receptor, however, qualitative differences have been recently discovered, and one glucocorticoid cannot be simply replaced by another (314). While hydrocortisone was initially chosen as the drug of choice for adrenal replacement, methylprednisolone may actually offer unique advantages over hydrocortisone as follows: (i) greater affinity for the glucocorticoid receptor (316); (ii) higher penetration in lung tissue (important for ARDS or pneumonia), and with longer residence time (317-319), (iii) higher potency of genomic activity especially NF- $\mathrm{B}$ inhibitory activity (320); and (iv) higher potency of non-genomic activity (321). GR $\alpha$ binding affinity, expressed as relative receptor affinity (RRA), correlates with glucocorticoid potency. The log RRAs for selected glucocorticoids are $0.95,1.62$, and 2.0 for hydrocortisone, methylprednisolone, and dexamethasone, respectively (316). A comparison study between these three types of glucocorticoids is needed.

The suggested mode of administration for septic shock [hydrocortisone $<400 \mathrm{mg} /$ day for $>3$ days (315), or hydrocortisone $50 \mathrm{mg}$ QID for 7 days without tapering] is based in part on an outdated pathophysiological model and a misconception about the risk associated with longer duration of treatment (small) and discontinuation without tapering (high). There is some evidence that a treatment duration of 3-7 days directed at reducing acuity of illness (transient reduction in systemic inflammation) might shortchange the full beneficial effects of glucocorticoid therapy (322). The impact of a longer duration of treatment on medium- and long-term mortality, as observed in RTCs of patients with Pneumocystis jiroveci pneumonia (323), needs to be investigated.

While glucocorticoids have an important role in supporting homeostatic corrections, this is achieved at the expense of reversible suppression of the HPA axis. In addition, the risk of glucocorticoid treatment-associated adrenal suppression in critically ill patients with dysregulated systemic inflammation is underappreciated. It has been shown that neither the total or the highest dose, nor the duration of glucocorticoid treatment is a significant predictor of HPA axis recovery (324). In the 
recent "Reduction in the Use of Corticosteroids in Exacerbated COPD trial" that evaluated prednisone $40 \mathrm{mg}$ daily for 5 or 14 days, adrenal suppression was detected at hospital discharge and at 30 days in 38 and $9 \%$ of patients, respectively; no differences were detected between 5 or 14 days of glucocorticoid exposure (325). Similarly to the experimental literature (326, 327), critical care RCTs have shown that abrupt glucocorticoid discontinuation after a 3-to-14 days treatment was rapidly followed by a reconstituted inflammatory response with a clinical relapse in approximately one-third of the patients (233, 322, 328, 329), and increased mortality (329). In the LaSRS trial (329), discontinuation of study drug $48 \mathrm{~h}$ postextubation was associated with clinical relapse in one-quarter of methylprednisolone-treated patients. These patients were rapidly returned to mechanical ventilation (MV) without reinstitution of study treatment, fared poorly, required additional days of MV and had a 9-fold increased risk of 60-day mortality $(p=0.001)$ in comparison to patients that did not return to MV (330). Gradual tapering is necessary to preserve the disease improvement achieved during glucocorticoid administration, to sustain continuous resolution and restoration of tissue homeostasis, to achieve gradual recovery of the suppressed HPA axis, to forestall disease relapse from reconstituted systemic inflammation, and finally to comply with the Food and Drug Administration package insert warnings (Reference ID: 3032293) (331).

With rapidly expanding knowledge, appreciation of how homeostatic corrections work and how they evolved provides a conceptual framework to understand and appreciate the complex pathobiology of critical illness. We have reviewed emerging literature clearly placing the activated $\mathrm{GR} \alpha$ at the center of the homeostatic corrections in the general adaptation to critical illness. Future research directions should include a reassessment of the pharmacological principles

\section{REFERENCES}

1. Galluzzi L, Yamazaki T, Kroemer G. Linking cellular stress responses to systemic homeostasis. Nat Rev Mol Cell Biol. (2018) 19:731-45. doi: 10.1038/s41580-018-0068-0

2. McEwen BS, Wingfield JC. The concept of allostasis in biology and biomedicine. Horm. Behav. (2003) 43:215. doi: 10.1016/S0018-506X(02)00024-7

3. Nylen ES, Muller B. Endocrine changes in critical illness. J. Intensive Care Med. (2004) 19:67-82. doi: 10.1177/0885066603259551

4. Nesse RM, Young EA. Evolutionary origins and functions of the stress response. J Encyclopedia Stress. (2000) 2:79-84.

5. Del Rey A, Besedovsky HO. Immune-neuro-endocrine reflexes, circuits, and networks: physiologic and evolutionary implications. Front Horm Res. (2017) 48:1-18. doi: 10.1159/000452902

6. Angelier F, Wingfield JC. Importance of the glucocorticoid stress response in a changing world: theory, hypotheses and perspectives. Gen Comp Endocrinol. (2013) 190:118-28. doi: 10.1016/j.ygcen.2013.05.022

7. Straub RH, Schradin C. Chronic inflammatory systemic diseases: an evolutionary trade-off between acutely beneficial but chronically harmful programs. Evol Med Public Health. (2016) 2016:37-51. doi: 10.1093/emph/eow001 that guide glucocorticoid treatment in critical illness and to devise co-interventions to improve cellular responsiveness to glucocorticoids by correcting conditions associated with a reduction in $\mathrm{GR} \alpha$ and mitochondrial concentration and function.

\section{SEARCH METHODOLOGY}

In addition to the previously used sources (17), we searched the Google Scholar and PubMed databases, employing the following keywords: "glucocorticoid," "corticosteroid," "glucocorticoid receptor," "stress response," "acute phase response," "regulation," "resolution," "critical illness related corticosteroid insufficiency," "treatment," “systemic inflammation," "dysregulated” systemic inflammation," "nuclear factor kappa B," "evolution," "endothelium," "mitochondria," "reactive oxygen species," ascorbic acid, thiamine, vitamin D, melatonin, "acute," "longterm," chronic," "homeostasis," "allostasis," "cacostasis," and terms related to critical illness, sepsis, septic shock, acute respiratory distress syndrome, "cardiac events." Manual searching of articles, including reference lists of cited publications, was also performed to avoid omissions.

\section{AUTHOR CONTRIBUTIONS}

GM conceived and initiated the article and wrote the original draft. GC contributed to the conception and worked on successive drafts.

\section{FUNDING}

This material was the result of work supported with the resources and use of facilities at the Memphis VA Medical Center. Funding for the respective trials was disclosed in the original publications.

8. Chrousos GP, Stress and disorders of the stress system. Nat Rev Endocrinol. (2009) 5:374-81. doi: 10.1038/nrendo.2009.106

9. Salminen A, Huuskonen J, Ojala J, Kauppinen A, Kaarniranta K, Suuronen T. Activation of innate immunity system during aging: NF-kB signaling is the molecular culprit of inflamm-aging. Ageing Res Rev. (2008) 7:83105. doi: 10.1016/j.arr.2007.09.002

10. Friedman R, Hughes AL. Molecular evolution of the NF-kappaB signaling system. Immunogenetics. (2002) 53:964-74. doi: 10.1007/s00251-00 1-0399-3

11. Meduri GU, Annane D, Chrousos GP, Marik PE, Sinclair SE. Activation and regulation of systemic inflammation in ARDS: rationale for prolonged glucocorticoid therapy. Chest. (2009) 136:1631-43. doi: 10.1378/chest.08-2408

12. Rao NA, McCalman MT, Moulos P, Francoijs KJ, Chatziioannou A, Kolisis FN, et al. Coactivation of GR and NFKB alters the repertoire of their binding sites and target genes. Genome Res. (2011) 21:140416. doi: $10.1101 /$ gr.118042.110

13. Yang $\mathrm{Y}, \mathrm{Wu} \mathrm{J}$, Wang JK. A database and functional annotation of NF-kappa B target genes. Int J Clin Exp Med. (2016) 9:7986-95.

14. Xiao W, Mindrinos MN, Seok J, Cuschieri J, Cuenca AG, Gao H, et al. A genomic storm in critically injured humans. J Exp Med. (2011) 208:258190. doi: 10.1084/jem.20111354 
15. Nicolaides NC, Kyratzi E, Lamprokostopoulou A, Chrousos GP, Charmandari E. Stress, the stress system and the role of glucocorticoids. Neuroimmunomodulation. (2015) 22:6-19. doi: 10.1159/000362736

16. LeGrand EK, Alcock J. Turning up the heat: immune brinksmanship in the acute-phase response. Q Rev Biol. (2012) 87:3-18. doi: 10.1086/663946

17. Annane D, Pastores S, Arlt W, Balk R, Beishuizen A, Briegel J, et al. Critical illness-related corticosteroid insufficiency (CIRCI): a narrative review from a multispecialty task force of the society of critical care medicine (SCCM) and the European Society of Intensive Care Medicine (ESICM). Crit Care Med. (2017) 45:2089-99. doi: 10.1097/CCM.0000000000002724

18. Hawkins RB, Raymond SL, Stortz JA, Horiguchi H, Brakenridge SC, Gardner A, et al. Chronic critical illness and the persistent inflammation, immunosuppression, catabolism syndrome. Front. Immunol. (2018) 9:1511. doi: 10.3389/fimmu.2018.01511

19. Elenkov IJ, Iezzoni DG, Daly A, Harris AG, Chrousos GP. Cytokine dysregulation, inflammation and well-being. Neuroimmunomodulation. (2005) 12:255-69. doi: 10.1159/000087104

20. Lichtnekert J, Kawakami T, Parks WC, Duffield JS. Changes in macrophage phenotype as the immune response evolves. Curr Opin Pharmacol. (2013) 13:555-64. doi: 10.1016/j.coph.2013.05.013

21. Picard M, Juster RP, McEwen BS. Mitochondrial allostatic load puts the 'gluc' back in glucocorticoids. Nat Rev Endocrinol. (2014) 10:30310. doi: $10.1038 /$ nrendo.2014.22

22. Headley AS, Tolley E, Meduri GU. Infections and the inflammatory response in acute respiratory distress syndrome. Chest. (1997) 111:130621. doi: $10.1378 /$ chest.111.5.1306

23. Fernandez-Serrano S, Dorca J, Coromines M, Carratala J, Gudiol F, Manresa F. Molecular inflammatory responses measured in blood of patients with severe community-acquired pneumonia. Clin Diagn Lab Immunol. (2003) 10:813-20. doi: 10.1128/CDLI.10.5.813-820.2003

24. Igonin AA, Armstrong VW, Shipkova M, Lazareva NB, Kukes VG, Oellerich M. Circulating cytokines as markers of systemic inflammatory response in severe community-acquired pneumonia. Clin Biochem. (2004) 37:2049. doi: 10.1016/j.clinbiochem.2003.11.001

25. El Solh, Pineda L, Bouquin P, Mankowski C. Determinants of short and long term functional recovery after hospitalization for community-acquired pneumonia in the elderly: role of inflammatory markers. BMC Geriatr. (2006) 6:12. doi: 10.1186/1471-2318-6-12

26. Kellum JA, Kong L, Fink MP, Weissfeld LA, Yealy DM, Pinsky $\mathrm{MR}$, et al. Understanding the inflammatory cytokine response in pneumonia and sepsis: results of the Genetic and Inflammatory Markers of Sepsis (GenIMS) study. Arch Intern Med. (2007) 167:1655-63. doi: 10.1001/archinte.167.15.1655

27. Lee YL, Chen W, Chen LY, Chen CH, Lin YC, Liang SJ, et al. Systemic and bronchoalveolar cytokines as predictors of in-hospital mortality in severe community-acquired pneumonia. J Crit Care. (2010) 25:176.e713. doi: 10.1016/j.jcrc.2009.05.002

28. Fernandez-Botran R, Uriarte SM, Arnold FW, Rodriguez-Hernandez L, Rane MJ, Peyrani P, et al. Contrasting inflammatory responses in severe and non-severe community-acquired pneumonia. Inflammation. (2014) 37:1158-66. doi: 10.1007/s10753-014-9840-2

29. Gomez HG, Gonzalez SM, Londono JM, Hoyos NA, Nino CD, Leon AL, et al. Immunological characterization of compensatory anti-inflammatory response syndrome in patients with severe sepsis: a longitudinal study* Crit Care Med. (2014) 42:771-80. doi: 10.1097/CCM.0000000000000100

30. van Vught LA, Wiewel MA, Hoogendijk AJ, Frencken JF, Scicluna BP, Klouwenberg $\mathrm{P}$, et al. The host response in patients with sepsis developing intensive care unit-acquired secondary infections. Am J Respir Crit Care Med. (2017) 196:458-70. doi: 10.1164/rccm.201606-1225OC

31. Meduri GU, Headley S, Kohler G, Stentz F, Tolley E, Umberger R, et al. Persistent elevation of inflammatory cytokines predicts a poor outcome in ARDS. Plasma IL-1 beta and IL-6 levels are consistent and efficient predictors of outcome over time. Chest. (1995) 107:106273. doi: $10.1378 /$ chest.107.4.1062

32. Meduri GU, Kohler G, Headley S, Tolley E, Stentz F, Postlethwaite A. Inflammatory cytokines in the BAL of patients with ARDS. Persistent elevation over time predicts poor outcome. Chest. (1995) 108:130314. doi: $10.1378 /$ chest.108.5.1303
33. Meduri GU, Muthiah MP, Carratu P, Eltorky M, Chrousos GP. Nuclear factor-kappaB- and glucocorticoid receptor alpha- mediated mechanisms in the regulation of systemic and pulmonary inflammation during sepsis and acute respiratory distress syndrome. Evidence for inflammation-induced target tissue resistance to glucocorticoids. Neuroimmunomodulation. (2005) 12:321-38. doi: 10.1159/000091126

34. Parsons PE, Eisner MD, Thompson BT, Matthay MA, Ancukiewicz M, Bernard GR, et al. Lower tidal volume ventilation and plasma cytokine markers of inflammation in patients with acute lung injury. Crit Care Med. (2005) 33:1-6; discussion: 230-2. doi: 10.1097/01.CCM.0000149854.61192.DC

35. Sinclair SE, Bijoy J, Golden E, Carratu P, Umberger R, Meduri GU. Interleukin-8 and soluble intercellular adhesion molecule-1 during acute respiratory distress syndrome and in response to prolonged methylprednisolone treatment. Minerva Pneumol. (2006) 45:93-104.

36. Aisiku IP, Yamal J-M, Doshi P, Benoit JS, Gopinath S, Goodman JC, et al. Plasma cytokines IL-6, IL-8, and IL-10 are associated with the development of acute respiratory distress syndrome in patients with severe traumatic brain injury. Crit Care. (2016) 20:1-10. doi: 10.1186/s13054-016-1470-7

37. Bohrer H, Qiu F, Zimmermann T, Zhang Y, Jllmer T, Mannel D, et al. Role of NF kappa B in the mortality of sepsis. J Clin Invest. (1997) 100:97285. doi: 10.1172/JCI119648

38. Paterson RL, Galley HF, Dhillon JK, Webster NR. Increased nuclear factor $\mathrm{kB}$ activation in critically ill patients who die. Crit Care Med. (2000) 28:104751. doi: 10.1097/00003246-200004000-00022

39. Arnalich F, Garcia-Palomero E, Lopez J, Jimenez M, Madero R, Renart $\mathrm{J}$, et al. Predictive value of nuclear factor kappaB activity and plasma cytokine levels in patients with sepsis. Infect Immun. (2000) 68:19425. doi: 10.1128/IAI.68.4.1942-1945.2000

40. Kinasewitz GT, Yan SB, Basson B, Comp P, Russell JA, Cariou A, et al. Universal changes in biomarkers of coagulation and inflammation occur in patients with severe sepsis, regardless of causative micro-organism [ISRCTN74215569]. Crit Care. (2004) 8:R82-90. doi: 10.1186/cc2459

41. Snijders D, Schoorl M, Schoorl M, Bartels PC, van der Werf TS, Boersma WG. D-dimer levels in assessing severity and clinical outcome in patients with community-acquired pneumonia. A secondary analysis of a randomised clinical trial. Eur J Intern Med. (2012) 23:43641. doi: 10.1016/j.ejim.2011.10.019

42. van Vught LA, Scicluna BP, Wiewel MA, Hoogendijk AJ, Klein Klouwenberg PM, Franitza $\mathrm{M}$, et al. Comparative analysis of the host response to community-acquired and hospital-acquired pneumonia in critically Ill patients. Am J Respir Crit Care Med. (2016) 194:1366-74. doi: 10.1164/rccm.201602-0368OC

43. Fiusa MML, Carvalho-Filho MA, Annichino-Bizzacchi JM, De Paula EV. Causes and consequences of coagulation activation in sepsis: an evolutionary medicine perspective. BMC Med. (2015) 13:105. doi: 10.1186/s12916-015-0327-2

44. Frank MG, Watkins LR, Maier SF. Stress-induced glucocorticoids as a neuroendocrine alarm signal of danger. Brain Behav Immun. (2013) 33:16. doi: 10.1016/j.bbi.2013.02.004

45. Yende S, D’Angelo G, Kellum JA, Weissfeld L, Fine J, Welch RD, et al. Inflammatory markers at hospital discharge predict subsequent mortality after pneumonia and sepsis. Am J Respir Crit Care Med. (2008) 177:12427. doi: 10.1164/rccm.200712-1777OC

46. Yende S, Kellum JA, Talisa VB, Palmer OMP, C.-Chang CH, Filbin MR, et al. Long-term host immune response trajectories among hospitalized patients with sepsis. JAMA Netw Open. (2019) 2:e198686. doi: 10.1001/jamanetworkopen.2019.8686

47. Riché F, Chousterman BG, Valleur P, Mebazaa A, Launay JM, Gayat E. Protracted immune disorders at one year after ICU discharge in patients with septic shock. Critical Care. (2018) 22:42. doi: 10.1186/s13054-017-1934-4

48. Miller AH. Inflammation versus glucocorticoids as purveyors of pathology during stress: have we reached the tipping point? Biol Psychiatry. (2008) 64:263-5. doi: 10.1016/j.biopsych.2008.05.018

49. Miller GE, Chen E, Sze J, Marin T, Arevalo JM, Doll R, et al. A functional genomic fingerprint of chronic stress in humans: blunted glucocorticoid and increased NF-kappaB signaling. Biol Psychiatry. (2008) 64:266-72. doi: 10.1016/j.biopsych.2008.03.017 
50. Kale SS, Yende S. Effects of aging on inflammation and hemostasis through the continuum of critical illness. Aging Dis. (2011) 2:501-11.

51. Winer L, Beckmann N, Veile RA, Goodman MD, Caldwell CC, Nomellini V. Consumptive coagulopathy is associated with organ dysfunction during PICS. Am J Physiol. (2019) 316:L946-52. doi: 10.1152/ajplung.00521.2018

52. Picca A, Lezza AMS, Leeuwenburgh C, Pesce V, Calvani R, Landi F, et al. Fueling inflamm-aging through mitochondrial dysfunction: mechanisms and molecular targets. Int J Mol Sci. (2017) 18:933. doi: 10.3390/ijms18050933

53. Lapp HE, Bartlett AA, and Hunter RG. Stress and glucocorticoid receptor regulation of mitochondrial gene expression. J Mol Endocrinol. (2019) 62:R121-8. doi: 10.1530/JME-18-0152

54. Pinti M, Cevenini E, Nasi M, De Biasi S, Salvioli S, Monti D, et al. Circulating mitochondrial DNA increases with age and is a familiar trait: implications for "inflamm-aging”. Eur J Immunol. (2014) 44:155262. doi: 10.1002/eji.201343921

55. Yende S, Linde-Zwirble W, Mayr F, Weissfeld LA, Reis S, Angus DC. Risk of cardiovascular events in survivors of severe sepsis. Am J Respir Crit Care Med. (2014) 189:1065-74. doi: 10.1164/rccm.201307-1321OC

56. Zannas AS, Jia M, Hafner K, Baumert J, Wiechmann T, Pape JC, et al. Epigenetic upregulation of FKBP5 by aging and stress contributes to NF- $\kappa \mathrm{B}-$ driven inflammation and cardiovascular risk. Proc Natl Acad Sci USA. (2019) 116:11370-9. doi: 10.1073/pnas.1816847116

57. Minejima E, Bensman J, She RC, Mack WJ, Tuan Tran M, Ny P, et al. A dysregulated balance of proinflammatory and anti-inflammatory host cytokine response early during therapy predicts persistence and mortality in Staphylococcus aureus bacteremia. Crit Care Med. (2015) 44:6719. doi: 10.1097/CCM.0000000000001465

58. Headley AS, Meduri GU, Tolley E. Stentz Infections F, SIRS, and CARS during ARDS and in response to prolonged glucocorticoid treatment [Abstract]. Am J Respir Crit Care Med. (2000) 161:A378.

59. Tang BM, Huang SJ, McLean AS. Genome-wide transcription profiling of human sepsis: a systematic review. Crit Care. (2010) 14:R237. doi: 10.1186/cc9392

60. Temel RE, Trigatti B, DeMattos RB, Azhar S, Krieger M, Williams DL. Scavenger receptor class $\mathrm{B}$, type I (SR-BI) is the major route for the delivery of high density lipoprotein cholesterol to the steroidogenic pathway in cultured mouse adrenocortical cells. Proc Natl Acad Sci USA. (1997) 94:13600-5. doi: 10.1073/pnas.94.25.13600

61. Chien JY, Jerng JS, Yu CJ, Yang PC. Low serum level of high-density lipoprotein cholesterol is a poor prognostic factor for severe sepsis. Crit Care Med. (2005) 33:1688-93. doi: 10.1097/01.CCM.0000171183.79525.6B

62. Gordon BR, Parker TS, Levine DM, Saal SD, Wang JC, Sloan BJ, et al. Relationship of hypolipidemia to cytokine concentrations and outcomes in critically ill surgical patients. Crit Care Med. (2001) 29:15638. doi: 10.1097/00003246-200108000-00011

63. Barlage S, Gnewuch C, Liebisch G, Wolf Z, Audebert FX, Gluck T, et al. Changes in HDL-associated apolipoproteins relate to mortality in human sepsis and correlate to monocyte and platelet activation. Intens Care Med. (2009) 35:1877-85. doi: 10.1007/s00134-009-1609-y

64. Cai L, Ji A, de Beer FC, Tannock LR, van der Westhuyzen DR. SR-BI protects against endotoxemia in mice through its roles in glucocorticoid production and hepatic clearance. J Clin Invest. (2008) 118:364-75. doi: 10.1172/JCI31539

65. van der Voort PH, Gerritsen RT, Bakker AJ, Boerma EC, Kuiper MA, de Heide L. HDL-cholesterol level and cortisol response to synacthen in critically ill patients. Intensive Care Med. (2003) 29:2199203. doi: 10.1007/s00134-003-2021-7

66. Laviolle B, Annane D, Fougerou C, Bellissant E. Gluco- and mineralocorticoid biological effects of a 7-day treatment with low doses of hydrocortisone and fludrocortisone in septic shock. Intensive Care Med. (2012) 38:1306-14. doi: 10.1007/s00134-012-2585-1

67. Chrousos GA. Hench Lecture Award: The Evolution of Glucocorticoids. In: 2010 ACR/ARHP Annual Scientific Meeting. Atlanta, GA: The Rheumatologist (2011).

68. Vandevyver S, Dejager L, Libert C. Comprehensive overview of the structure and regulation of the glucocorticoid receptor. Endocr Rev. (2014) 35:67193. doi: $10.1210 /$ er.2014-1010
69. Nicolaides NC, Charmandari E. Novel insights into the molecular mechanisms underlying generalized glucocorticoid resistance and hypersensitivity syndromes. Hormones. (2017) 16:124-38. doi: 10.14310/horm.2002.1728

70. Bridgham JT, Eick GN, Larroux C, Deshpande K, Harms MJ, Gauthier ME, et al. Protein evolution by molecular tinkering: diversification of the nuclear receptor superfamily from a ligand-dependent ancestor. PLoS Biol. (2010) 8:e1000497. doi: 10.1371/journal.pbio.1000497

71. Kino T. Glucocorticoid receptor. In: Feingold KR, Anawalt B, Boyce A, Chrousos G, Dungan K, Grossman A, Hershman JM, Kaltsas G, Koch C, Kopp P, Korbonits M, McLachlan R, Morley JE, New M, Perreault L, Purnell J, Rebar R, Singer F, Trence DL, Vinik A, Wilson DP, editors. Endotext. South Dartmouth, MA: MDText. com, Inc. (2017).

72. Whirledge SD, Oakley RH, Myers PH, Lydon JP, DeMayo F, Cidlowski JA. Uterine glucocorticoid receptors are critical for fertility in mice through control of embryo implantation and decidualization. Proc Natl Acad Sci USA. (2015) 112:15166-71. doi: 10.1073/pnas.1508056112

73. Rog-Zielinska EA, Thomson A, Kenyon CJ, Brownstein DG, Moran CM, Szumska D, et al. Glucocorticoid receptor is required for foetal heart maturation. Hum Mol Genet. (2013) 22:3269-82. doi: 10.1093/hmg/ddt182

74. Bird AD, McDougall AR, Seow B, Hooper SB, Cole TJ. Minireview: glucocorticoid regulation of lung development: lessons learned from conditional GR knockout mice. Mol Endocrinol. (2015) 29:158-71. doi: 10.1210/me.2014-1362

75. Oakley RH, Ramamoorthy S, Foley JF, Busada JT, Lu NZ, Cidlowski JA. Glucocorticoid receptor isoform-specific regulation of development, circadian rhythm, and inflammation in mice. FASEB J. (2018) 32:525871. doi: 10.1096/fj.201701153R

76. Stanton SC, Zilioli S, Briskin JL, Imami L, Tobin ET, Wildman DE, et al. Mothers' attachment is linked to their children's anti-inflammatory gene expression via maternal warmth. Soc Psychol Pers Sci. (2017) 8:796805. doi: 10.1177/1948550616687125

77. Jiang CL, Liu L, Tasker JG. Why do we need nongenomic glucocorticoid mechanisms? Front Neuroendocrinol. (2014) 35:72-5. doi: 10.1016/j.yfrne.2013.09.005

78. Ozaki T, Yasuoka S, Nakayama T, Tsubura E. Glucocorticoid receptors, in human alveolar macrophages and peripheral blood cells. Clin Exp Immunol. (1982) 47:505-11.

79. Vassiliou AG, Floros G, Jahaj E, Stamogiannos G, Gennimata S, Vassiliadi DA, et al. Decreased glucocorticoid receptor expression during critical illness. Eur J Clin Invest. (2019) 49:e13073. doi: 10.1111/eci.13073

80. Sacta MA, Chinenov Y, Rogatsky I. Glucocorticoid signaling: an update from a genomic perspective. Annu Rev Physiol. (2016) 78:155-80. doi: 10.1146/annurev-physiol-021115-105323

81. Polman JAE, Welten JE, Bosch DS, de Jonge RT, Balog J, van der Maarel SM, et al. A genome-wide signature of glucocorticoid receptor binding in neuronal PC12 cells. BMC Neurosci. (2012) 13:118. doi: 10.1186/1471-2202-13-118

82. Lee SR, Kim HK, Song IS, Youm J, Dizon LA, Jeong SH, et al. Glucocorticoids and their receptors: insights into specific roles in mitochondria. Prog Biophys Mol Biol. (2013) 112:44-54. doi: 10.1016/j.pbiomolbio.201 3.04 .001

83. Hunter RG, Seligsohn M, Rubin TG, Griffiths BB, Ozdemir Y, Pfaff DW, et al. Stress and corticosteroids regulate rat hippocampal mitochondrial DNA gene expression via the glucocorticoid receptor. Proc Natl Acad Sci USA. (2016) 113:9099-104. doi: 10.1073/pnas.1602185113

84. Galon J, Franchimont D, Hiroi N, Frey G, Boettner A, Ehrhart-Bornstein $M$, et al. Gene profiling reveals unknown enhancing and suppressive actions of glucocorticoids on immune cells. FASEB J. (2002) 16:6171. doi: 10.1096/fj.01-0245com

85. Gonzales LW, Guttentag SH, Wade KC, Postle AD, Ballard PL. Differentiation of human pulmonary type II cells in vitro by glucocorticoid plus cyclic AMP. Am J Physiol Lung Cell Mol Physiol. (2002) 283:L940-51. doi: 10.1152/ajplung.00127.2002

86. Cruz-Topete D, He B, Xu X, Cidlowski JA. Krüppel-like factor 13 is a major mediator of glucocorticoid receptor signaling in cardiomyocytes and protects these cells from DNA damage and death. J Biol Chem. (2016) 291:19374-86. doi: 10.1074/jbc.M116.725903 
87. Le PP, Friedman JR, Schug J, Brestelli JE, Parker JB, Bochkis IM, et al. Glucocorticoid receptor-dependent gene regulatory networks. PLoS Genet. (2005) 1:e16. doi: 10.1371/journal.pgen.0010016

88. He B, Cruz-Topete D, Oakley RH, Xiao X, Cidlowski JA. Human glucocorticoid receptor $\beta$ regulates gluconeogenesis and inflammation in mouse liver. Mol Cell Biol. (2016) 36:714-30. doi: 10.1128/MCB.00908-15

89. Ishmael FT, Fang X, Houser KR, Pearce K, Abdelmohsen K, Zhan $M$, et al. The human glucocorticoid receptor as an RNA-binding protein: global analysis of glucocorticoid receptor-associated transcripts and identification of a target RNA motif. J Immunol. (2011) 186:118998. doi: 10.4049/jimmunol.1001794

90. Dejager L, Pinheiro I, Puimege L, Fan YD, Gremeaux L, Vankelecom H, et al. Increased glucocorticoid receptor expression and activity mediate the LPS resistance of SPRET/EI mice. J Biol Chem. (2010) 285:3107386. doi: 10.1074/jbc.M110.154484

91. Munck A, Guyre PM, Holbrook NJ. Physiological functions of glucocorticoids in stress and their relation to pharmacological actions. Endocr Rev. (1984) 5:25-44. doi: 10.1210/edrv-5-1-25

92. Busillo JM, Cidlowski JA. The five Rs of glucocorticoid action during inflammation: ready, reinforce, repress, resolve, and restore. Trends Endocrinol Metab. (2013) 24:109-19. doi: 10.1016/j.tem.2012.11.005

93. Busillo JM, Azzam KM, Cidlowski JA. Glucocorticoids sensitize the innate immune system through regulation of the NLRP3 inflammasome. J Biol Chem. (2011) 286:38703-13. doi: 10.1074/jbc.M111.275370

94. Gruys E, Toussaint MJ, Niewold TA, Koopmans SJ. Acute phase reaction and acute phase proteins. J Zhejiang Univ Sci B. (2005) 6:104556. doi: 10.1631/jzus.2005.B1045

95. Hermus AR, Sweep CG. Cytokines and the hypothalamicpituitary-adrenal axis. J. Steroid Biochem Mol Biol. (1990) 37:867-71. doi: 10.1016/0960-0760(90)90434-M

96. Perlstein RS, Whitnall MH, Abrams JS, Mougey EH, Neta R. Synergistic roles of interleukin-6, interleukin-1, and tumor necrosis factor in the adrenocorticotropin response to bacterial lipopolysaccharide in $\begin{array}{lllll}\text { vivo. Endocrinology. (1993) } & 132: 946-52 . & \text { doi: } & 10.1210 / \text { endo.132.3.8 }\end{array}$ 382602

97. Mikhaylova IV, Kuulasmaa T, Jaaskelainen J, Voutilainen R. Tumor necrosis factor-alpha regulates steroidogenesis, apoptosis, and cell viability in the human adrenocortical cell line NCI-H295R. Endocrinology. (2007) 148:38692. doi: 10.1210/en.2006-0726

98. Engstrom L, Rosen K, Angel A, Fyrberg A, Mackerlova L, Konsman JP, et al. Systemic immune challenge activates an intrinsically regulated local inflammatory circuit in the adrenal gland. Endocrinology. (2008) 149:143650. doi: 10.1210/en.2007-1456

99. Cai TQ, Wong B, Mundt SS, Thieringer R, Wright SD, Hermanowski-Vosatka A. Induction of 11beta-hydroxysteroid dehydrogenase type 1 but not-2 in human aortic smooth muscle cells by inflammatory stimuli. J Steroid Biochem Mol Biol. (2001) 77:117-22. doi: 10.1016/S0960-0760(01)00041-3

100. Lannan EA, Galliher-Beckley AJ, Scoltock AB, Cidlowski JA. Proinflammatory actions of glucocorticoids: glucocorticoids and TNF $\alpha$ coregulate gene expression in vitro and in vivo. Endocrinology. (2012) 153:3701-12. doi: 10.1210/en.2012-1020

101. Dejager L, Vandevyver S, Petta I, Libert C. Dominance of the strongest: inflammatory cytokines versus glucocorticoids. Cytokine Growth Factor Rev. (2014) 25:21-33. doi: 10.1016/j.cytogfr.2013.12.006

102. Meduri GU, Kanangat S, Bronze M, Patterson DR, Meduri CU, Pak C, et al. Effects of methylprednisolone on intracellular bacterial growth. Clin Diagn Lab Immunol. (2001) 8:1156-63. doi: 10.1128/CDLI.8.6.1156-1163.2001

103. Meduri GU, Tolley EA, Chrousos GP, Stentz F. Prolonged methylprednisolone treatment suppresses systemic inflammation in patients with unresolving acute respiratory distress syndrome. Evidence for inadequate endogenous glucocorticoid secretion and inflammation-induced immune cell resistance to glucocorticoids. Am J Respir Crit Care Med. (2002) 165:983-91. doi: 10.1164/ajrccm.165.7.2106014

104. Newton R, Leigh R, Giembycz MA. Pharmacological strategies for improving the efficacy and therapeutic ratio of glucocorticoids in inflammatory lung diseases. Pharmacol Ther. (2010) 125:286327. doi: 10.1016/j.pharmthera.2009.11.003
105. Kadmiel M, Cidlowski JA. Glucocorticoid receptor signaling in health and disease. Trends Pharmacol. Sci. (2013) 34:51830. doi: 10.1016/j.tips.2013.07.003

106. Hapgood JP, Avenant C, Moliki JM. Glucocorticoid-independent modulation of GR activity: implications for immunotherapy. Pharmacol Ther. (2016) 165:93-113. doi: 10.1016/j.pharmthera.2016.06.002

107. Perretti M, D'Acquisto F. Annexin A1 and glucocorticoids as effectors of the resolution of inflammation. Nat Rev Immunol. (2009) 9:6270. doi: $10.1038 /$ nri2470

108. Vago JP, Nogueira CR, Tavares LP, Soriani FM, Lopes F, Russo RC, et al. Annexin A1 modulates natural and glucocorticoid-induced resolution of inflammation by enhancing neutrophil apoptosis. J Leukoc Biol. (2012) 92:249-58. doi: 10.1189/jlb.0112008

109. Vago JP, Tavares LP, Garcia CC, Lima KM, Perucci LO, Vieira EL, et al. The role and effects of glucocorticoid-induced leucine zipper in the context of inflammation resolution. J Immunol. (2015) 194:494050. doi: 10.4049/jimmunol.1401722

110. Liu Y, Cousin JM, Hughes J, van Damme J, Seckl JR, Haslett C, et al. Glucocorticoids promote nonphlogistic phagocytosis of apoptotic leukocytes. J Immunol. (1999) 162:3639-46.

111. Heasman SJ, Giles KM, Ward C, Rossi AG, Haslett C, Dransfield I. Glucocorticoid-mediated regulation of granulocyte apoptosis and macrophage phagocytosis of apoptotic cells: implications for the resolution of inflammation. J Endocrinol. (2003) 178:29-36. doi: 10.1677/joe.0.1780029

112. McColl A, Bournazos S, Franz S, Perretti M, Morgan BP, Haslett C, et al. Glucocorticoids induce protein S-dependent phagocytosis of apoptotic neutrophils by human macrophages. J Immunol. (2009) 183:216775. doi: 10.4049/jimmunol.0803503

113. Ehrchen J, Steinmuller L, Barczyk K, Tenbrock K, Nacken W, Eisenacher $\mathrm{M}$, et al. Glucocorticoids induce differentiation of a specifically activated, anti-inflammatory subtype of human monocytes. Blood. (2007) 109:126574. doi: 10.1182/blood-2006-02-001115

114. Schif-Zuck S, Gross N, Assi S, Rostoker R, Serhan CN, Ariel A. Saturated-efferocytosis generates pro-resolving CD11blow macrophages: Modulation by resolvins and glucocorticoids. Eur J Immunol. (2011) 41:36639. doi: 10.1002/eji.201040801

115. Gilmour JS, Coutinho AE, Cailhier JF, Man TY, Clay M, Thomas $\mathrm{G}$, et al. Local amplification of glucocorticoids by 11 betahydroxysteroid dehydrogenase type 1 promotes macrophage phagocytosis of apoptotic leukocytes. J Immunol. (2006) 176:7605-11. doi: 10.4049/jimmunol.176.12.7605

116. Chapman KE, Coutinho A, Gray M, Gilmour JS, Savill JS, Seckl JR. Local amplification of glucocorticoids by 11beta-hydroxysteroid dehydrogenase type 1 and its role in the inflammatory response. Ann N Y Acad Sci. (2006) 1088:265-73. doi: 10.1196/annals.1366.030

117. Barczyk K, Ehrchen J, Tenbrock K, Ahlmann M, Kneidl J, Viemann D, et al. Glucocorticoids promote survival of anti-inflammatory macrophages via stimulation of adenosine receptor A3. Blood. (2010) 116:44655. doi: 10.1182/blood-2009-10-247106

118. Maderna P, Yona S, Perretti M, Godson C. Modulation of phagocytosis of apoptotic neutrophils by supernatant from dexamethasone-treated macrophages and annexin-derived peptide Ac(2-26). J Immunol. (2005) 174:3727-33. doi: 10.4049/jimmunol.174.6.3727

119. Ariel A, Serhan CN. New lives given by cell death: macrophage differentiation following their encounter with apoptotic leukocytes during the resolution of inflammation. Front Immunol. (2012) 3:4. doi: 10.3389/fimmu.2012.00004

120. Dendoncker K, Libert C. Glucocorticoid resistance as a major drive in sepsis pathology. Cytokine Growth Factor Rev. (2017) 35:85-96. doi: 10.1016/j.cytogfr.2017.04.002

121. Meduri GU, Yates CR. Systemic inflammation-associated glucocorticoid resistance and outcome of ARDS. Ann N Y Acad Sci. (2004) 1024:2453. doi: 10.1196/annals.1321.004

122. Téblick A, Peeters B, Langouche L, van den Berghe G. Adrenal function and dysfunction in critically ill patients. Nat Rev Endocrinol. (2019) 1:41727. doi: 10.1038/s41574-019-0185-7

123. Webster JC, Oakley RH, Jewell CM, Cidlowski JA. Proinflammatory cytokines regulate human glucocorticoid receptor gene expression and lead 
to the accumulation of the dominant negative beta isoform: a mechanism for the generation of glucocorticoid resistance. Proc Natl Acad Sci USA. (2001) 98:6865-70. doi: 10.1073/pnas. 121455098

124. Bergquist M, Nurkkala M, Rylander C, Kristiansson E, Hedenstierna G, Lindholm C. Expression of the glucocorticoid receptor is decreased in experimental Staphylococcus aureus sepsis. J Infect. (2013) 67:57483. doi: $10.1016 /$ j.jinf.2013.07.028

125. Abraham MN, Jimenez DM, Fernandes TD, Deutschman CS. Cecal ligation and puncture alters glucocorticoid receptor expression. Crit Care Med. (2018) 46:e797-804. doi: 10.1097/CCM.0000000000003201

126. Stith RD, McCallum RE. Down regulation of hepatic glucocorticoid receptors after endotoxin treatment. Infect Immun. (1983) 40:61321. doi: 10.1128/IAI.40.2.613-621.1983

127. Da J, Chen L, Hedenstierna G. Nitric oxide up-regulates the glucocorticoid receptor and blunts the inflammatory reaction in porcine endotoxin sepsis. Crit Care Med. (2007) 35:26-32. doi: 10.1097/01.CCM.0000250319.91575.BB

128. Zhou T, Fan XM, Wang YQ, Qi YJ, Chen H, Qian SY. [Effects of different doses of hydrocortisone on acute lung injury in rats with early septic shock induced by Escherichia coli]. Zhonghua Er Ke Za Zhi. (2004) 42:644-8.

129. Zhang Y, Zuo W, Rong Q, Teng G, Zhang YM. Glucocorticoid receptor expression on acute lung injury induced by endotoxin in rats. World J Emerg Med. (2010) 1:65-9.

130. Goodwin JE, Feng Y, Velazquez H, Sessa WC. Endothelial glucocorticoid receptor is required for protection against sepsis. Proc Natl Acad Sci USA. (2013) 110:306-11. doi: 10.1073/pnas.1210200110

131. Kamiyama K, Matsuda N, Yamamoto S, Takano K, Takano Y, Yamazaki H, et al. Modulation of glucocorticoid receptor expression, inflammation, and cell apoptosis in septic guinea pig lungs using methylprednisolone. Am J Physiol Lung Cell Mol Physiol. (2008) 295:L998-1006. doi: 10.1152/ajplung.00459.2007

132. Wang XQ, Zhou X, Zhou Y, Rong L, Gao L, Xu W. Low-dose dexamethasone alleviates lipopolysaccharide-induced acute lung injury in rats and upregulates pulmonary glucocorticoid receptors. Respirology. (2008) 13:772-80. doi: 10.1111/j.1440-1843.2008.01344.x

133. Reichardt HM, Umland T, Bauer A, Kretz O, Schutz G. Mice with an increased glucocorticoid receptor gene dosage show enhanced resistance to stress and endotoxic shock. Mol Cell Biol. (2000) 20:9009-17. doi: 10.1128/MCB.20.23.9009-9017.2000

134. Siebig S, Meinel A, Rogler G, Klebl E, Wrede CE, Gelbmann C, et al. Decreased cytosolic glucocorticoid receptor levels in critically ill patients. Anaesth Intensive Care. (2010) 38:13340. doi: $10.1177 / 0310057 \mathrm{X} 1003800122$

135. van den Akker ELT, Koper JW, Joosten K, de Jong FH, Hazelzet JA, Lamberts SWJ, et al. Glucocorticoid receptor mRNA levels are selectively decreased in neutrophils of children with sepsis. Intensive care Med. (2009) 35:1247-54. doi: 10.1007/s00134-009-1468-6

136. Indyk JA, Candido-Vitto C, Wolf IM, Venkataraman S, Munoz R, Saladino RA, et al. Reduced glucocorticoid receptor protein expression in children with critical illness. Horm Res Paediatr. (2013) 79:16978. doi: $10.1159 / 000348290$

137. Ledderose C, Mohnle P, Limbeck E, Schutz S, Weis F, Rink J, et al. Corticosteroid resistance in sepsis is influenced by microRNA-124-induced downregulation of glucocorticoid receptor-alpha. Crit Care Med. (2012) 40:2745-53. doi: 10.1097/CCM.0b013e31825b8ebc

138. Peeters RP, Hagendorf A, Vanhorebeek I, Visser TJ, Klootwijk W, Mesotten $\mathrm{D}$, et al. Tissue mRNA expression of the glucocorticoid receptor and its splice variants in fatal critical illness. Clin Endocrinol. (2009) 71:14553. doi: 10.1111/j.1365-2265.2008.03443.x

139. Murray JF, Matthay MA, Luce JM, Flick MR. An expanded definition of the adult respiratory distress syndrome. Am Rev Respir Dis. (1988) 138:7203. doi: $10.1164 /$ ajrccm/138.3.720

140. Zielinska KA, van Moortel L, Opdenakker G, de Bosscher K,van den Steen PE. Endothelial response to glucocorticoids in inflammatory diseases. Front Immunol. (2016) 7:592. doi: 10.3389/fimmu.201 6.00592

141. Chelazzi C, Villa G, Mancinelli P, de Gaudio AR, Adembri C. Glycocalyx and sepsis-induced alterations in vascular permeability. Crit Care. (2015) 19:26. doi: 10.1186/s13054-015-0741-z
142. Hue CD, Cho FS, Cao S, Dale Bass CR, Meaney DF, Morrison B. Dexamethasone potentiates in vitro blood-brain barrier recovery after primary blast injury by glucocorticoid receptor-mediated upregulation of ZO-1 tight junction protein. J Cereb Blood Flow Metab. (2015) 35:11918. doi: $10.1038 / \mathrm{jcbfm} .2015 .38$

143. Hendrickson CM, Matthay MA. Endothelial biomarkers in human sepsis: pathogenesis and prognosis for ARDS. Pulm Circ. (2018) 8:2045894018769876. doi: $10.1177 / 2045894018769876$

144. Parikh SM. Dysregulation of the angiopoietin-Tie-2 axis in sepsis ARDS. Virulence. (2013) 4:517-24. doi: 10.4161/viru.24906

145. Ricciuto DR, Dos Santos CC, Hawkes M, Toltl LJ, Conroy AL, Rajwans N, et al. Angiopoietin-1 and angiopoietin-2 as clinically informative prognostic biomarkers of morbidity and mortality in severe sepsis. Crit Care Med. (2011) 39:702-10. doi: 10.1097/CCM.0b013e318206d285

146. Hughes CG, Pandharipande PP, Thompson JL, Chandrasekhar R, Ware LB, Ely EW, et al. Endothelial activation and blood-brain barrier injury as risk factors for Delirium in critically Ill patients. Crit Care Med. 44:e809-17 (2016) doi: 10.1097/CCM.0000000000001739

147. Oudemans-van Straaten HM, Spoelstra-de Man AM, de Waard MC. Vitamin C revisited. Crit Care. (2014) 18:460. doi: 10.1186/s13054-014-0460-x

148. De Backer D, Donadello K, Taccone FS, Ospina-Tascon G, Salgado D, Vincent JL. Microcirculatory alterations: potential mechanisms and implications for therapy. Ann Intensive Care. (2011) 1:27. doi: 10.1186/2110-5820-1-27

149. Kanczkowski W, Sue M, Zacharowski K, Reincke M, Bornstein SR. The role of adrenal gland microenvironment in the HPA axis function and dysfunction during sepsis. Mol Cell Endocrinol. (2015) 408:2418. doi: 10.1016/j.mce.2014.12.019

150. Ware LB, Conner ER, Matthay MA. Von Willebrand factor antigen is an independent marker of poor outcome in patients with early acute lung injury. Crit Care Med. (2001) 29:2325-31. doi: 10.1097/00003246-200112000-00016

151. van der Flier M, van Leeuwen HJ, van Kessel KP, Kimpen JL, Hoepelman AI, Geelen SP, et al. Plasma vascular endothelial growth factor in severe sepsis. Shock. (2005) 23:35-8. doi: 10.1097/01.shk.0000150728.91155.41

152. Mutunga M, Fulton B, Bullock R, Batchelor A, Gascoigne A, Gillespie JI, et al. Circulating endothelial cells in patients with septic shock. Am J Respir Crit Care Med. (2001) 163:195-200. doi: 10.1164/ajrccm.163.1.9912036

153. Moussa MD, Santonocito C, Fagnoul D, Donadello K, Pradier O, Gaussem P, et al. Evaluation of endothelial damage in sepsis-related ARDS using circulating endothelial cells. Intensive Care Med. (2015) 41:2318. doi: 10.1007/s00134-014-3589-9

154. De Backer D, Donadello K, Sakr Y, Ospina-Tascon G, Salgado D, Scolletta S, et al. Microcirculatory alterations in patients with severe sepsis: impact of time of assessment and relationship with outcome. Crit Care Med. (2013) 41:791-9. doi: 10.1097/CCM.0b013e3182742e8b

155. Cronstein BN, Kimmel SC, Levin RI, Martiniuk F, Weissmann G. A mechanism for the antiinflammatory effects of corticosteroids: the glucocorticoid receptor regulates leukocyte adhesion to endothelial cells and expression of endothelial-leukocyte adhesion molecule 1 and intercellular adhesion molecule 1. Proc Natl Acad Sci USA. (1992) 89:9991-5. doi: 10.1073/pnas.89.21.9991

156. Salvador E, Shityakov S, Forster C. Glucocorticoids and endothelial cell barrier function. Cell Tissue Res. (2014) 355:597605. doi: 10.1007/s00441-013-1762-z

157. Vettorazzi S, Bode C, Dejager L, Frappart L, Shelest E, Klassen C, et al. Glucocorticoids limit acute lung inflammation in concert with inflammatory stimuli by induction of SphK1. Nat Commun. (2015) 6:7796. doi: $10.1038 /$ ncomms8796

158. Kim H, Lee JM, Park JS, Jo SA, Kim YO, Kim CW, et al. Dexamethasone coordinately regulates angiopoietin-1 and VEGF: a mechanism of glucocorticoid-induced stabilization of blood-brain barrier. Biochem Biophys Res Commun. (2008) 372:243-8. doi: 10.1016/j.bbrc.2008.05.025

159. Ferrelli F, Pastore D, Capuani B, Lombardo MF, Blot-Chabaud M, Coppola A, et al. Serum glucocorticoid inducible kinase (SGK)-1 protects endothelial cells against oxidative stress and apoptosis induced by hyperglycaemia. Acta Diabetol. (2015) 52:55-64. doi: 10.1007/s00592-014-0600-4

160. Basello K, Pacifici F, Capuani B, Pastore D, Lombardo MF, Ferrelli F, et al. Serum- and glucocorticoid-inducible kinase 1 delay the onset of 
endothelial senescence by directly interacting with human telomerase reverse transcriptase. Rejuvenation Res. (2016) 19:79-89. doi: 10.1089/rej.2015.1726

161. Hahn RT, Hoppstadter J, Hirschfelder K, Hachenthal N, Diesel B, Kessler $\mathrm{SM}$, et al. Downregulation of the glucocorticoid-induced leucine zipper (GILZ) promotes vascular inflammation. Atherosclerosis. (2014) 234:391400. doi: 10.1016/j.atherosclerosis.2014.03.028

162. Bouazza Y, Sennoun N, Strub C, Regnault V, Gibot S, Meziani F, et al. Comparative effects of recombinant human activated protein $\mathrm{C}$ and dexamethasone in experimental septic shock. Intensive Care Med. (2011) 37:1857-64. doi: 10.1007/s00134-011-2327-9

163. Limbourg FP, Huang Z, Plumier JC, Simoncini T, Fujioka M, Tuckermann $J$, et al. Rapid nontranscriptional activation of endothelial nitric oxide synthase mediates increased cerebral blood flow and stroke protection by corticosteroids. J Clin Invest. (2002) 110:1729-38. doi: 10.1172/JCI0215481

164. Hafezi-Moghadam A, Simoncini T, Yang Z, Limbourg FP, Plumier JC, Rebsamen MC, et al. Acute cardiovascular protective effects of corticosteroids are mediated by non-transcriptional activation of endothelial nitric oxide synthase. Nat Med. (2002) 8:473-9. doi: 10.1038/nm0502-473

165. Chappell D, Jacob M, Hofmann-Kiefer K, Bruegger D, Rehm M, Conzen $\mathrm{P}$, et al. Hydrocortisone preserves the vascular barrier by protecting the endothelial glycocalyx. Anesthesiology. (2007) 107:77684. doi: 10.1097/01.anes.0000286984.39328.96

166. Chappell D, Hofmann-Kiefer K, Jacob M, Rehm M, Briegel J, Welsch U, et al. TNF-alpha induced shedding of the endothelial glycocalyx is prevented by hydrocortisone and antithrombin. Basic Res Cardiol. (2009) 104:7889. doi: 10.1007/s00395-008-0749-5

167. Aytac HO, Iskit AB, Sayek I. Dexamethasone effects on vascular flow and organ injury in septic mice. J Surg Res. (2014) 188:496502. doi: 10.1016/j.jss.2014.01.040

168. Yang S, Zhang L. Glucocorticoids and vascular reactivity. Curr Vasc Pharmacol. (2004) 2:1-12. doi: 10.2174/1570161043476483

169. Radomski MW, Palmer RM, Moncada S. Glucocorticoids inhibit the expression of an inducible, but not the constitutive, nitric oxide synthase in vascular endothelial cells. Proc Natl Acad Sci USA. (1990) 87:100437. doi: 10.1073/pnas.87.24.10043

170. Buchele GL, Silva E, Ospina-Tascon GA, Vincent JL, Backer DD. Effects of hydrocortisone on microcirculatory alterations in patients with septic shock. Crit Care Med. (2009) 37:1341-7. doi: 10.1097/CCM.0b013e3181986647

171. Rinaldi S, Adembri C, De Gaudio AR. Low-dose hydrocortisone during severe sepsis: effects on microalbuminuria. Crit Care Med. (2006) 34:23349. doi: 10.1097/01.CCM.0000233872.04706.BB

172. Meduri GU, Headley S, Tolley E, Shelby M, Stentz F, Postlethwaite A. Plasma and BAL cytokine response to corticosteroid rescue treatment in late ARDS. Chest. (1995) 108:1315-25. doi: 10.1378/chest.108.5.1315

173. Seam N, Meduri GU, Wang H, Nylen ES, Sun J, Schultz MJ, et al. Effects of methylprednisolone infusion on markers of inflammation, coagulation, and angiogenesis in early acute respiratory distress syndrome. Crit Care Med. (2012) 40:495-501. doi: 10.1097/CCM.0b013e318232da5e

174. Fadel F, Andre-Gregoire G, Gravez B, Bauvois B, Bouchet S, SierraRamos C, et al. Aldosterone and vascular mineralocorticoid receptors in murine endotoxic and human septic shock. Crit Care Med. (2017) 45:e95462. doi: $10.1097 / C C M .0000000000002462$

175. Nowicki S. Biology: The Science of Life Course Guidebook. Chantilly, VA: The Great Courses Chantilly (2004).

176. Sagan L. On the origin of mitosing cells. J Theor Biol. (1967) 14:255-74.

177. Margulis L. Symbiosis in Cell Evolution: Life and Its Environment on the Early Earth. Boston, MA: NASA; Boston University (1981).

178. Ballinger SW. Beyond retrograde and anterograde signalling: mitochondrial-nuclear interactions as a means for evolutionary adaptation and contemporary disease susceptibility. Biochem Soc Trans. (2013) 41:111-7. doi: 10.1042/BST20120227

179. Meduri GU. The role of the host defence response in the progression and outcome of ARDS: pathophysiological correlations and response to glucocorticoid treatment. Eur Respir J. (1996) 9:2650-70. doi: 10.1183/09031936.96.09122650

180. Picard M, McManus MJ, Gray JD, Nasca C, Moffat C, Kopinski $\mathrm{PK}$, et al. Mitochondrial functions modulate neuroendocrine, metabolic, inflammatory, and transcriptional responses to acute psychological stress. Proc Natl Acad Sci USA. (2015) 112:E6614-23. doi: 10.1073/pnas.1515733112

181. Picard M, McEwen BS, Epel ES, Sandi C. An energetic view of stress: focus on mitochondria. Front Neuroendocrinol. (2018) 49:7285. doi: 10.1016/j.yfrne.2018.01.001

182. Nunnari J, Suomalainen A. Mitochondria: in sickness and in health. Cell. (2012) 148:1145-59. doi: 10.1016/j.cell.2012.02.035

183. Manoli I, Alesci S, Blackman MR, Su YA, Rennert OM, Chrousos GP. Mitochondria as key components of the stress response. Trends Endocrinol Metab. (2007) 18:190-8. doi: 10.1016/j.tem.2007.04.004

184. Galluzzi L, Kepp O, Kroemer G. Mitochondria: master regulators of danger signalling. Nat Rev Mol Cell Biol. (2012) 13:780-8. doi: 10.1038/nrm3479

185. Taverne YJ, Merkus D, Bogers AJ, Halliwell B, Duncker DJ, Lyons TW. Reactive oxygen species: radical factors in the evolution of animal life: a molecular timescale from Earth's earliest history to the rise of complex life. Bioessays. (2018) 40:1700158. doi: 10.1002/bies.201700158

186. Singer M. The role of mitochondrial dysfunction in sepsis-induced multiorgan failure. Virulence. (2014) 5:66-72. doi: 10.4161/viru.26907

187. Tang VM, Young AH, Tan H, Beasley C, Wang JF. Glucocorticoids increase protein carbonylation and mitochondrial dysfunction. Horm Metab Res. (2013) 45:709-15. doi: 10.1055/s-0033-1345119

188. Paupe V, Prudent J. New insights into the role of mitochondrial calcium homeostasis in cell migration. Biochem Biophys Res Commun. (2018) 500:7586. doi: 10.1016/j.bbrc.2017.05.039

189. Picca A, Lezza AMS, Leeuwenburgh C, Pesce V, Calvani R, Bossola M, et al. Circulating mitochondrial DNA at the crossroads of mitochondrial dysfunction and inflammation during aging and muscle wasting disorders. Rejuvenation Res. (2018) 21:350-9. doi: 10.1089/rej.2017.1989

190. Du J, Wang Y, Hunter R, Wei YL, Blumenthal R, Falke C, et al. Dynamic regulation of mitochondrial function by glucocorticoids. Proc Natl Acad Sci USA. (2009) 106:3543-8. doi: 10.1073/pnas.0812671106

191. Schumacker PT, Gillespie MN, Nakahira K, Choi AMK, Crouser ED, Piantadosi CA, et al. Mitochondria in lung biology and pathology: more than just a powerhouse. Am J Physiol Lung C. (2014) 306:L96274. doi: 10.1152/ajplung.00073.2014

192. Kasahara E, Inoue M. Cross-talk between HPA-axis-increased glucocorticoids and mitochondrial stress determines immune responses and clinical manifestations of patients with sepsis. Redox Rep. (2015) 20:1-10. doi: 10.1179/1351000214Y.0000000107

193. Singer M, de Santis V, Vitale D, Jeffcoate W. Multiorgan failure is an adaptive, endocrine-mediated, metabolic response to overwhelming systemic inflammation. Lancet. (2004) 364:5458. doi: 10.1016/S0140-6736(04)16815-3

194. Mantzarlis K, Tsolaki V, Zakynthinos E. Role of oxidative stress and mitochondrial dysfunction in sepsis and potential therapies. Oxid Med Cell Longev. (2017) 2017:5985209. doi: 10.1155/2017/5985209

195. Nakamori Y, Koh T, Ogura H, Tanaka H, Fujimi S, Kasai K, et al. Enhanced expression of intranuclear NF-kappa B in primed polymorphonuclear leukocytes in systemic inflammatory response syndrome patients. J Trauma. (2003) 54:253-60. doi: 10.1097/01.TA.0000037096.73714.E6

196. Ristow M, Schmeisser K. Mitohormesis: promoting health and lifespan by increased levels of Reactive Oxygen Species (ROS). Dose Response. (2014) 12:288-341. doi: 10.2203/dose-response.13-035.Ristow

197. Galley HF. Oxidative stress mitochondrial dysfunction in sepsis. $\mathrm{Br} \mathrm{J}$ Anaesth. (2011) 107:57-64. doi: 10.1093/bja/aer093

198. Costa NA, Gut AL, Dorna MD, Pimentel JAC, Cozzolino SMF, Azevedo PS, et al. Serum thiamine concentration and oxidative stress as predictors of mortality in patients with septic shock. J Crit Care. (2014) 29:24952. doi: 10.1016/j.jcrc.2013.12.004

199. Lasky-Su J, Dahlin A, Litonjua AA, Rogers AJ, McGeachie MJ, Baron RM, et al. Metabolome alterations in severe critical illness and Vitamin D status. Crit Care. (2017) 21:193. doi: 10.1186/s13054-017-1794-y

200. Oudemans-van Straaten HM, Elbers PWG, Spoelstra-de Man AME. How to give vitamin $\mathrm{C}$ a cautious but fair chance in severe sepsis. Chest. (2017) 151:1199-200. doi: 10.1016/j.chest.2017.01.008

201. Picard M, Wallace DC, Burelle Y. The rise of mitochondria in medicine. Mitochondrion. (2016) 30:105-16. doi: 10.1016/j.mito.2016.07.003 
202. Singer M, Brealey D. Mitochondrial dysfunction in sepsis. Biochem Soc Symp. (1999) 66:149-166. doi: 10.1042/bss0660149

203. Brealey D, Brand M, Hargreaves I, Heales S, Land J, Smolenski $\mathrm{R}$, et al. Association between mitochondrial dysfunction and severity and outcome of septic shock. Lancet. (2002) 360:21923. doi: 10.1016/S0140-6736(02)09459-X

204. Matkovich SJ, Al Khiami B, Efimov IR, Evans S, Vader J, Jain A, et al. Widespread down-regulation of cardiac mitochondrial and sarcomeric genes in patients with sepsis. Crit Care Med. (2017) 45:40714. doi: $10.1097 /$ CCM.0000000000002207

205. Kraft BD, Chen L, Suliman HB, Piantadosi CA, Welty-Wolf KE. Peripheral blood mononuclear cells demonstrate mitochondrial damage clearance during sepsis. Crit Care Med. (2019) 47:6518. doi: 10.1097/CCM.0000000000003681

206. Chen Y, Luo G, Yuan J, Wang Y, Yang X, Wang X, et al. Vitamin C mitigates oxidative stress and tumor necrosis factor-alpha in severe communityacquired pneumonia and LPS-induced macrophages. Mediators Inflamm. (2014) 2014:426740. doi: 10.1155/2014/426740

207. Hoffmann RF, Jonker MR, Brandenburg SM, de Bruin HG, Ten Hacken NHT, van Oosterhout AJM, et al. Mitochondrial dysfunction increases pro-inflammatory cytokine production and impairs repair and corticosteroid responsiveness in lung epithelium. Sci Rep. (2019) 9:15047. doi: 10.1038/s41598-019-51517-x

208. Wang CN, Duan GL, Liu YJ, Yu Q, Tang XL, Zhao W, et al. Overproduction of nitric oxide by endothelial cells and macrophages contributes to mitochondrial oxidative stress in adrenocortical cells and adrenal insufficiency during endotoxemia. Free Radic Biol Med. (2015) 83:31-40. doi: 10.1016/j.freeradbiomed.2015.02.024

209. Zhang Q, Raoof M, Chen Y, Sumi Y, Sursal T, Junger W, et al. Circulating mitochondrial DAMPs cause inflammatory responses to injury. Nature. (2010) 464:104-7. doi: 10.1038/nature08780

210. Nakahira K, Kyung S-Y, Rogers AJ, Gazourian L, Youn S, Massaro AF, et al. Circulating mitochondrial DNA in patients in the ICU as a marker of mortality: derivation and validation. PLoS Med. (2013) 10:e1001577. doi: 10.1371/journal.pmed.1001577

211. Johansson PI, Nakahira K, Rogers AJ, McGeachie MJ, Baron RM, Fredenburgh LE, et al. Plasma mitochondrial DNA and metabolomic alterations in severe critical illness. Crit Care. (2018) 22:360. doi: 10.1186/s13054-018-2275-7

212. Pyle A, Burn DJ, Gordon C, Swan C, Chinnery PF, Baudouin SV. Fall in circulating mononuclear cell mitochondrial DNA content in human sepsis. Intensive Care Med. (2010) 36:956-62. doi: 10.1007/s00134-010-1823-7

213. Fariss MW, Chan CB, Patel M, van Houten B, Orrenius S. Role of mitochondria in toxic oxidative stress. Mol Interv. (2005) 5:94111. doi: 10.1124/mi.5.2.7

214. Forceville X, Aouizerate P, Guizard M. [Septic shock and selenium administration]. Therapie. (2001) 56:653-61.

215. Psarra AM, Sekeris CE. Glucocorticoid receptors and other nuclear transcription factors in mitochondria and possible functions. Biochim Biophys Acta. (2009) 1787:431-6. doi: 10.1016/j.bbabio.2008.11.011

216. Psarra AM, Sekeris CE. Glucocorticoids induce mitochondrial gene transcription in HepG2 cells: role of the mitochondrial glucocorticoid receptor. Biochim Biophys Acta. (2011) 1813:181421. doi: 10.1016/j.bbamcr.2011.05.014

217. Gero D, Szabo C. Glucocorticoids suppress mitochondrial oxidant production via upregulation of uncoupling protein 2 in hyperglycemic endothelial cells. PLoS ONE. (2016) 11:e0154813. doi: 10.1371/journal.pone.0154813

218. Yamawaki H, Haendeler J, Berk BC. Thioredoxin: a key regulator of cardiovascular homeostasis. Circ Res. (2003) 93:1029-33. doi: 10.1161/01.RES.0000102869.39150.23

219. Psarra AM, Hermann S, Panayotou G, Spyrou G. Interaction of mitochondrial thioredoxin with glucocorticoid receptor and NF-kappaB modulates glucocorticoid receptor and NF-kappaB signalling in HEK-293 cells. Biochem J. (2009) 422:521-31. doi: 10.1042/BJ20090107

220. Makino Y, Okamoto K, Yoshikawa N, Aoshima M, Hirota K, Yodoi J, et al. Thioredoxin: a redox-regulating cellular cofactor for glucocorticoid hormone action. Cross talk between endocrine control of stress response and cellular antioxidant defense system. J Clin Invest. (1996) 98:246977. doi: 10.1172/JCI119065

221. Polito A, Sonneville R, Guidoux C, Barrett L, Viltart O, Mattot V, et al. Changes in CRH and ACTH synthesis during experimental and human septic shock. PLoS ONE. (2011) 6:e25905. doi: 10.1371/journal.pone.0025905

222. Peeters B, Meersseman P, Vander Perre S, Wouters PJ, Vanmarcke D, Debaveye $\mathrm{Y}$, et al. Adrenocortical function during prolonged critical illness and beyond: a prospective observational study. Intens Care Med. (2018) 44:1720-1729. doi: 10.1007/s00134-018-5366-7

223. Jennewein C, Tran N, Kanczkowski W, Heerdegen L, Kantharajah A, Drose S, et al. Mortality of septic mice strongly correlates with adrenal gland inflammation. Crit Care Med. (2015) 44:e190-9. doi: 10.1055/s-0035-1547679

224. Hutchison KA, Matic G, Meshinchi S, Bresnick EH, Pratt WB. Redox manipulation of DNA binding activity and BuGR epitope reactivity of the glucocorticoid receptor. J Biol Chem. (1991) 266:10505-9.

225. Okamoto K, Tanaka H, Makino Y, Makino I. Restoration of the glucocorticoid receptor function by the phosphodiester compound of vitamins $\mathrm{C}$ and E, EPC-K1 (L-ascorbic acid 2-[3,4-dihydro-2,5,7,8tetramethyl-2-(4,8,12-trimethyltridecyl)-2H-1-benzopyran-6 -yl hydrogen phosphate] potassium salt), via a redox-dependent mechanism. Biochem Pharmacol. (1998) 56:79-86. doi: 10.1016/S0006-2952(98)00121-X

226. Hakim A, Barnes PJ, Adcock IM, Usmani OS. Importin-7 mediates glucocorticoid receptor nuclear import and is impaired by oxidative stress, leading to glucocorticoid insensitivity. FASEB J. (2013) 27:451019. doi: $10.1096 /$ fj.12-222604

227. Duma D, Silva-Santos JE, Assreuy J. Inhibition of glucocorticoid receptor binding by nitric oxide in endotoxemic rats. Crit Care Med. (2004) 32:230410. doi: 10.1097/01.CCM.0000145996.57901.D7

228. Liu MY, Zhu LJ, Zhou QG. Neuronal nitric oxide synthase is an endogenous negative regulator of glucocorticoid receptor in the hippocampus. Neurol Sci. (2013) 34:1167-72. doi: 10.1007/s10072-012-1213-8

229. Okamoto K, Tanaka H, Ogawa H, Makino Y, Eguchi H, Hayashi S, et al. Redox-dependent regulation of nuclear import of the glucocorticoid receptor. J Biol Chem. (1999) 274:10363-71. doi: 10.1074/jbc.274.15.10363

230. Galigniana MD, Piwien-Pilipuk G, Assreuy J. Inhibition of glucocorticoid receptor binding by nitric oxide. Mol Pharmacol. (1999) 55:317-23.

231. Long F, Wang Y-X, Liu L, Zhou J, Cui R-Y, Jiang CL. Rapid nongenomic inhibitory effects of glucocorticoids on phagocytosis and superoxide anion production by macrophages. Steroids. (2005) 70:5561. doi: 10.1016/j.steroids.2004.10.004

232. Choi HM, Jo SK, Kim SH, Lee JW, Cho E, Hyun YY, et al. Glucocorticoids attenuate septic acute kidney injury. Biochem Biophys Res Commun. (2013) 435:678-84. doi: 10.1016/j.bbrc.2013.05.042

233. Keh D, Weber-Cartens S, Schulz C, Ahlers O, Bercker S, Volk $\mathrm{HD}$, et al. Immunologic and hemodynamic effects of "low-dose" hydrocortisone in septic shock: a double-blind, randomized, placebocontrolled, crossover study. Am J Respir Crit Care Med. (2003) 167:512-20. doi: 10.1164/rccm.200205-446OC

234. Kaufmann I, Briegel J, Schliephake F, Hoelzl A, Chouker A, Hummel T, et al. Stress doses of hydrocortisone in septic shock: beneficial effects on opsonization-dependent neutrophil functions. Intensive Care Med. (2008) 34:344-9. doi: 10.1007/s00134-007-0868-8

235. Li Y, Cui X, Li X, Solomon SB, Danner RL, Banks SM, et al. Risk of death does not alter the efficacy of hydrocortisone therapy in a mouse E. coli pneumonia model : risk and corticosteroids in sepsis. Intensive Care Med. (2007) 34:568-77. doi: 10.1007/s00134-007-0921-7

236. Amrein K, Oudemans-van Straaten HM, Berger MM. Vitamin therapy in critically ill patients: focus on thiamine, vitamin C, Vitamin D. Intensive Care Med. (2018) 44:1940-4. doi: 10.1007/s00134-01 8-5107-y

237. Moskowitz A, Andersen LW, Huang DT, Berg KM, Grossestreuer AV, Marik PE, et al. Ascorbic acid, corticosteroids, and thiamine in sepsis: a review of the biologic rationale and the present state of clinical evaluation. Crit Care. (2018) 22:283. doi: 10.1186/s13054-018-2217-4

238. Collie JT, Greaves RF, Jones OA, Lam Q, Eastwood GM, Bellomo R. Vitamin B1 in critically ill patients: needs and challenges. Clin Chem Lab Med. (2017) 5:1652-68. doi: 10.1515/cclm-2017-0054 
239. Donnino MW, Andersen LW, Chase M, Berg KM, Tidswell M, Giberson T, et al. Randomized, double-blind, placebo-controlled trial of thiamine as a metabolic resuscitator in septic shock: a pilot study. Crit Care Med. (2016) 44:360-7. doi: 10.1097/CCM.0000000000001572

240. Donnino MW, Carney E, Cocchi MN, Barbash I, Chase M, Joyce N, et al. Thiamine deficiency in critically ill patients with sepsis. J Crit Care. (2010) 25:576-81. doi: 10.1016/j.jcrc.2010.03.003

241. Corcoran TB, O'Neill MA, Webb SA, Ho KM. Prevalence of vitamin deficiencies on admission: relationship to hospital mortality in critically ill patients. Anaesth Intensive Care. (2009) 37:254-60. doi: 10.1177/0310057X0903700215

242. Woolum JA, Abner EL, Kelly A, Thompson Bastin ML, Morris PE, Flannery AH. Effect of thiamine administration on lactate clearance and mortality in patients with septic shock. Crit Care Med. (2018) 46:174752. doi: 10.1097/CCM.0000000000003311

243. Christopher KB. Vitamin D and critical illness outcomes. Curr Opin Crit Care. (2016) 22:332-8. doi: 10.1097/MCC.0000000000000328

244. Chirumbolo S, Bjorklund G, Sboarina A, Vella A. The role of Vitamin $\mathrm{D}$ in the immune system as a pro-survival molecule. Clin Ther. (2017) 39:894-916. doi: 10.1016/j.clinthera.2017.03.021

245. Wobke TK, Sorg BL, Steinhilber D. Vitamin D in inflammatory diseases. Front Physiol. (2014) 5:244. doi: 10.3389/fphys.2014.00244

246. Stio M, Martinesi M, Bruni S, Treves C, Mathieu CA. The Vitamin D analogue TX 527 blocks NF-kappaB activation in peripheral blood mononuclear cells of patients with Crohn's disease. J Steroid Biochem Mol Biol. (2007) 103:51-60. doi: 10.1016/j.jsbmb.2006.07.008

247. Zhang Y, Leung DY, Goleva E. Vitamin D enhances glucocorticoid action in human monocytes: involvement of granulocyte-macrophage colonystimulating factor and mediator complex subunit 14. J Biol Chem. (2013) 288:14544-53. doi: 10.1074/jbc.M112.427054

248. Calton EK, Keane KN, Newsholme P, Soares MJ. The impact of Vitamin D levels on inflammatory status: a systematic review of immune cell studies. PLoS ONE. (2015) 10:e0141770. doi: 10.1371/journal.pone.0141770

249. Greulich T, Regner W, Branscheidt M, Herr C, Koczulla AR, Vogelmeier CF, et al. Altered blood levels of Vitamin D, cathelicidin and parathyroid hormone in patients with sepsis-a pilot study. Anaesth Intensive Care. (2017) 45:36-45. doi: 10.1177/0310057X1704500106

250. Kassel O, Sancono A, Krätzschmar J, Kreft B, Stassen M, Cato AC. Glucocorticoids inhibit MAP kinase via increased expression and decreased degradation of MKP-1. EMBO J. (2001) 20:7108-16. doi: 10.1093/emboj/20.24.7108

251. Zhang Y, Leung DY, Richers BN, Liu Y, Remigio LK, Riches DW, et al. Vitamin D inhibits monocyte/macrophage proinflammatory cytokine production by targeting MAPK phosphatase-1. J Immunol. (2012) 188:212735. doi: 10.4049/jimmunol.1102412

252. Zhang Y, Leung DYM, Goleva E. Anti-inflammatory and corticosteroidenhancing actions of Vitamin D in monocytes of patients with steroidresistant and those with steroid-sensitive asthma. J Allergy Clin Immunol. (2014) 133:1744-52.e1. doi: 10.1016/j.jaci.2013.12.004

253. Kassi E, Nasiri-Ansari N, Papavassiliou AG. Vitamin D affects glucocorticoid action in target cells. Oncotarget. (2017) 8:7220-1. doi: 10.18632/oncotarget.13997

254. Grimes DS. Are statins analogues of Vitamin D? Lancet. (2006) 368:836. doi: 10.1016/S0140-6736(06)68971-X

255. Bagnoud M, Hoepner R, Pistor M, Salmen A, Schrewe L, Guse K, et al. Vitamin D augments glucocorticosteroid efficacy via inhibition of mTORc1. Multiple Sclerosis J. (2018) 24:33-4.

256. Ojaimi S, Skinner NA, Strauss BJ, Sundararajan V, Woolley I, Visvanathan K. Vitamin D deficiency impacts on expression of tolllike receptor-2 and cytokine profile: a pilot study. J Transl Med. (2013) 11:176. doi: 10.1186/1479-5876-11-176

257. Bouillon R, Verstuyf A. Vitamin D, Mitochondria, And Muscle. Oxford: Oxford University Press (2013).

258. Jain SK, Micinski D. Vitamin D upregulates glutamate cysteine ligase and glutathione reductase, GSH formation. and decreases ROS and MCP-1 and IL-8 secretion in high-glucose exposed U937 monocytes. Biochem Biophys Res Commun. (2013) 437:7-11. doi: 10.1016/j.bbrc.2013.06.004
259. Ryan ZC, Craig TA, Folmes CD, Wang X, Lanza IR, Schaible NS, et al. $1 \alpha$, 25-Dihydroxyvitamin D3 regulates mitochondrial oxygen consumption and dynamics in human skeletal muscle cells. J Biol Chem. (2016) 291:151428. doi: 10.1074/jbc.M115.684399

260. Sinha A, Hollingsworth KG, Ball S, Cheetham T. Improving the Vitamin D status of Vitamin D deficient adults is associated with improved mitochondrial oxidative function in skeletal muscle. J Clin Endocrino Metab. (2013) 98:E509-13. doi: 10.1210/jc.2012-3592

261. Czarnik T, Czarnik A, Gawda R, Gawor M, Piwoda M, Marszalski $M$, et al. Vitamin $D$ kinetics in the acute phase of critical illness: a prospective observational study. J Crit Care. (2018) 43:294-9. doi: 10.1016/j.jcrc.2017.09.179

262. Amrein K. Martucci G, Mcnally JD. When not to use meta-analysis: analysing the meta-analyses on Vitamin D in critical care. Clin Nutr. (2017) 36:1729-30. doi: 10.1016/j.clnu.2017.08.009

263. Amrein K, Schnedl C, Holl A, Riedl R, Christopher KB, Pachler C, et al Effect of high-dose Vitamin D3 on hospital length of stay in critically ill patients with Vitamin D deficiency: the VITdAL-ICU randomized clinical trial. JAMA. (2014) 312:1520-30. doi: 10.1001/jama.2014.13204

264. National Heart, Lung, and Blood Institute PETAL Clinical Trials Network, Ginde AA, Brower RG, Caterino JM, Finck L, Banner-Goodspeed VM, et al. Early high-dose Vitamin D3 for critically ill, Vitamin D-deficient patients. $N$ Engl J Med. (2019) 381:2529-40. doi: 10.1056/NEJMoa1911124

265. Li Y, Li G. Is vitamin C beneficial to patients with CAP? Curr Infect Dis Rep. (2016) 18:1-6. doi: 10.1007/s11908-016-0530-0

266. Drouin G, Godin JR, Page B. The genetics of vitamin C loss in vertebrates. Curr Genomics. (2011) 12:371-8. doi: 10.2174/138920211796429736

267. Marik PE. Vitamin C for the treatment of sepsis: the scientific rationale. Pharmacol Ther. (2018) 189:63-70. doi: 10.1016/j.pharmthera.2018.04.007

268. Padayatty S, Levine M. Vitamin C: the known and the unknown and Goldilocks. Oral Dis. (2016) 22:463-93. doi: 10.1111/odi.12446

269. Ang A, Pullar JM, Currie MJ, Vissers MCM. Vitamin C and immune cell function in inflammation and cancer. Biochem Soc Trans. (2018) 46:114759. doi: 10.1042/BST20180169

270. Palsson-McDermott EM, O'neill LA. The Warburg effect then and now: from cancer to inflammatory diseases. J Bioessays. (2013) 35:96573. doi: 10.1002/bies.201300084

271. Sorice A, Guerriero E, Capone F, Colonna G. Ascorbic acid: its role in immune system and chronic inflammation diseases. Mini Rev Med Chem. (2014) 14:444-52. doi: 10.2174/1389557514666140428112602

272. Patak P, Willenberg HS, Bornstein SR. Vitamin C is an important cofactor for both adrenal cortex and adrenal medulla. Endocr Res. (2004) 30:8715. doi: 10.1081/ERC-200044126

273. Bjorkhem I, Kallner A, Karlmar KE. Effects of ascorbic acid deficiency on adrenal mitochondrial hydroxylations in guinea pigs. J Lipid Res. (1978) 19:695-704

274. Fujita I, Hirano J, Itoh N, Nakanishi T, Tanaka K. Dexamethasone induces sodium-dependant vitamin $\mathrm{C}$ transporter in a mouse osteoblastic cell line MC3T3-E1. Br J Nutr. (2001) 86:145-9. doi: 10.1079/BJN2001406

275. Marik PE, Khangoora V, Rivera R, Hooper MH, Catravas Hydrocortisone J. Vitamin C, and thiamine for the treatment of severe sepsis and septic shock: a retrospective before-after study. Chest. (2017) 151:122938. doi: 10.1016/j.chest.2016.11.036

276. Hooper MH, Carr A, Marik PE. The adrenal-vitamin C axis: from fish to guinea pigs and primates. Crit Care. (2019) 23:29. doi: 10.1186/s13054-019-2332-x

277. Bowie AG, O'Neill LA. Vitamin C inhibits NF- $\mathrm{B}$ activation by TNF via the activation of p38 mitogen-activated protein kinase. J Immunol. (2000) 165:7180-8. doi: 10.4049/jimmunol.165.12.7180

278. Cárcamo JM, Pedraza A, Bórquez-Ojeda O, Golde DW. Vitamin C suppresses $\mathrm{TNF} \alpha$-induced $\mathrm{NF} \kappa \mathrm{B}$ activation by inhibiting I $\mathrm{B} \alpha$ phosphorylation. J Biochem. (2002) 41:12995-3002. doi: 10.1021/bi0 263210

279. Zhou G, Kamenos G, Pendem S, Wilson JX, Wu F. Ascorbate protects against vascular leakage in cecal ligation and puncture-induced septic peritonitis. Am J Physiol Regul Integr Comp Physiol. (2012) 302:R40916. doi: 10.1152/ajpregu.00153.2011 
280. Marik PE. Glucocorticosteroids as adjunctive therapy for acute respiratory distress syndrome and sepsis? yes, but not as monotherapy. Crit Care Med. (2017) 45:910-11. doi: 10.1097/CCM.0000000000002346

281. Fowler AA, Syed AA, Knowlson S, Sculthorpe R, Farthing D, DeWilde C, et al. Phase I safety trial of intravenous ascorbic acid in patients with severe sepsis. J Transl Med. (2014) 12:32. doi: 10.1186/1479-5876-12-32

282. Marik PE, Hooper MH. Doctor-your septic patients have scurvy! Crit Care. (2018) 22:23. doi: 10.1186/s13054-018-1950-z

283. Zabet MH, Mohammadi M, Ramezani M, Khalili H. Effect of high-dose ascorbic acid on vasopressor's requirement in septic shock. J Res Pharm Pract. (2016) 5:94-100. doi: 10.4103/2279-042X.179569

284. Fowler AA, Truwit JD, Hite RD, Morris PE, DeWilde C, Priday A, et al. Effect of vitamin $C$ infusion on organ failure and biomarkers of inflammation and vascular injury in patients with sepsis and severe acute respiratory failure: the CITRIS-ALI randomized clinical trial. JAMA. (2019) 322:126170. doi: 10.1001/jama.2019.11825

285. Headland SE, Norling LV. The resolution of inflammation: principles and challenges. Semin Immunol. (2015) 27:149160. doi: 10.1016/j.smim.2015.03.014

286. Bergquist M, Jirholt $P$, Nurkkala M, Rylander C, Hedenstierna G, Lindholm C. Glucocorticoid receptor function is decreased in neutrophils during endotoxic shock. J Infect. (2014) 69:113-22. doi: 10.1016/j.jinf.2014.03.011

287. Herasevich S, Odeyemi Y, Wieruszewski P, Gajic O, Yadav H. 1161: Timeliness of corticosteroid use in icu patients with pneumonia and ards. Crit Care Med. (2019) 47:557. doi: 10.1097/01.ccm.0000551906.96335.48

288. Prabhu VA, Awasthi S, Shanavas R, Kunhikatta V, Thunga G, Nair S, et al. Efficacy of corticosteroids in acute respiratory distress syn-drome: an observational study. J. Young Pharm. (2017) 9:65-68. doi: 10.5530/jyp.2017.9.13

289. Katsenos CS, Antonopoulou AN, Apostolidou EN, Ioakeimidou A, Kalpakou GT, Papanikolaou MN, et al. early administration of hydrocortisone replacement after the advent of septic shock: impact on survival and immune response*. Crit Care Med. (2014) 42:1651-7. doi: 10.1097/CCM.0000000000000318

290. Park HY, Suh GY, Song JU, Yoo H, Jo IJ, Shin TG, et al. Early initiation of low-dose corticosteroid therapy in the management of septic shock: a retrospective observational study. Crit Care. (2012) 16:R3. doi: 10.1186/cc10601

291. Confalonieri M, Meduri GU. Glucocorticoid treatment in community-acquired pneumonia. Lancet. (2011) 377:19824. doi: 10.1016/S0140-6736(11)60777-0

292. Annane D, Renault A, Brun-Buisson C, Megarbane B, Quenot JP, Siami S, et al. Hydrocortisone plus fludrocortisone for adults with septic shock. $N$ Engl J Med. (2018) 378:809-18. doi: 10.1056/NEJMoa1705716

293. Heming NM, Sivanandamoorthy SM, Meng PM, Bounab RM, Annane DM. Immune effects of corticosteroids in sepsis. Front Immunol. (2018) 9:1736. doi: 10.3389/fimmu.2018.01736

294. Landry DW, Levin HR, Gallant EM, Ashton RC Jr, Seo S. Vasopressin deficiency contributes to the vasodilation of septic shock. Circulation. (1997) 95:1122-5. doi: 10.1161/01.CIR.95.5.1122

295. Sharshar T, Blanchard A, Paillard M, Raphael JC, Gajdos P, Annane D. Circulating vasopressin levels in septic shock. Crit Care Med. (2003) 31:1752-8. doi: 10.1097/01.CCM.0000063046.82359.4A

296. Russell JA, Walley KR, Gordon AC, Cooper DJ, Hebert PC, Singer J, et al. Dieter ayers for the, and I. Septic shock trial, interaction of vasopressin infusion, corticosteroid treatment, and mortality of septic shock. Crit Care Med. (2009) 37:811-8. doi: 10.1097/CCM.0b013e3181961ace

297. National Center for Biotechnology Information. PubChem Database. Fludrocortisone, $\mathrm{CID}=31378$. Available online at: https://pubchem.ncbi. nlm.nih.gov/compound/31378 (accessed May 9, 2019).

298. Venkatesh B, Finfer S, Cohen J, Rajbhandari D, Arabi Y, Bellomo R, et al. The Australian-New Zealand intensive care society clinical trials, adjunctive glucocorticoid therapy in patients with septic shock. N Engl J Med. (2018) 378:797-808. doi: 10.1056/NEJMoa1705835

299. Takano K, Yamamoto S, Tomita K, Takashina M, Yokoo H, Matsuda N, et al. Successful treatment of acute lung injury with pitavastatin in septic mice: potential role of glucocorticoid receptor expression in alveolar macrophages. J Pharmacol Exp Ther. (2011) 336:381-90. doi: 10.1124/jpet.110.171462
300. Komatsubara M, Hara T, Hosoya T, Toma K, Tsukamoto-Yamauchi N, Iwata $\mathrm{N}$, et al. Melatonin regulates catecholamine biosynthesis by modulating bone morphogenetic protein and glucocorticoid actions. J Steroid Biochem Mol Biol. (2016) 165(Pt B):182-9. doi: 10.1016/j.jsbmb.2016.06.002

301. Hong J, Guo W-Z, Yan Z-H, Di L, Lu C-L. Influence of drug treatment on glucocorticoid receptor levels in patients with coronary heart disease. Chin Med J. (2010) 123:1685-89.

302. Souffriau J, Libert C. Mechanistic insights into the protective impact of zinc on sepsis. Cytokine Growth Factor Rev. (2017) 39:92-101. doi: 10.1016/j.cytogfr.2017.12.002

303. Erol N, Saglam L, Saglam YS, Erol HS, Altun S, Aktas MS, et al. The protection potential of antioxidant vitamins against acute respiratory distress syndrome: a rat trial. Inflammation. (2019) 42:1585-94. doi: 10.1007/s10753-019-01020-2

304. Meduri GU. An historical review of glucocorticoid treatment in sepsis. Disease pathophysiology and the design of treatment investigation. Sepsis. (1999) 3:21-38. doi: 10.1023/A:1009870524359

305. Meduri GU, Bridges L, Shih MC, Marik PE, Siemieniuk RAC, Kocak M. Prolonged glucocorticoid treatment is associated with improved ARDS outcomes: analysis of individual patients' data from four randomized trials and trial-level meta-analysis of the updated literature. Intensive Care Med. (2016) 42:829-40. doi: 10.1007/s00134-015-4095-4

306. Schulz KF, Moher D, Altman DG. CONSORT 2010 comments. Lancet. (2010) 376:1222-3. doi: 10.1016/S0140-6736(10)61879-X

307. Guyatt GH, Oxman AD, Vist GE, Kunz R, Falck-Ytter Y, AlonsoCoello P, et al. GRADE: an emerging consensus on rating quality of evidence and strength of recommendations. BMJ. (2008) 336:9246. doi: 10.1136/bmj.39489.470347.AD

308. Burton T. Why Cheap Drugs That Appear to Halt Fatal Sepsis Go Unused. New York, NY: The Wall Street Journal (2002).

309. Buttgereit F, da Silva JA, Boers M, Burmester GR, Cutolo M, Jacobs J, et al. Standardised nomenclature for glucocorticoid dosages and glucocorticoid treatment regimens: current questions and tentative answers in rheumatology. Ann Rheum Dis. (2002) 61:718-22. doi: 10.1136/ard.61.8.718

310. Ibarra-Estrada MA, Chávez-Peña Q, Reynoso-Estrella CI, Rios-Zermeño J, Aguilera-González PE, García-Soto MA, et al. Timing, method and discontinuation of hydrocortisone administration for septic shock patients. World J Crit Care Med. (2017) 6:65-73. doi: 10.5492/wjccm.v6.i1.65

311. Weber-Carstens S, Keh D. Bolus or continuous hydrocortisone-that is the question. Crit Care. (2007) 11:113. doi: 10.1186/cc5669

312. Loisa P, Parviainen I, Tenhunen J, Hovilehto S, Ruokonen E. Effect of mode of hydrocortisone administration on glycemic control in patients with septic shock: a prospective randomized trial. Crit Care. (2007) 11:R21. doi: 10.1186/cc5696

313. Cain DW, Cidlowski JA. Immune regulation by glucocorticoids. Nat Rev Immunol. (2017) 17:233-247. doi: 10.1038/nri.2017.1

314. Czock D, Keller F, Rasche FM, Haussler U. Pharmacokinetics and pharmacodynamics of systemically administered glucocorticoids. Clin Pharmacokinetics. (2005) 44:6198. doi: 10.2165/00003088-200544010-00003

315. Annane D, Pastores S, Rochwerg B, Arlt W, Balk R, Beishuizen A, et al. Guidelines for the diagnosis and management of critical illnessrelated corticosteroid insufficiency (CIRCI) in critically ill patients (Part I): society of critical care medicine (SCCM) and European Society of Intensive Care Medicine (ESICM) (2017) Crit Care Med. (2017) 45:2078-88. doi: 10.1097/CCM.0000000000002737

316. Mager DE, Moledina N, Jusko WJ. Relative immunosuppressive potency of therapeutic corticosteroids measured by whole blood lymphocyte proliferation. J Pharm Sci. (2003) 92:1521-5. doi: 10.1002/jps. 10402

317. Braude AC, Rebuck AS. Prednisone and methylprednisolone disposition in the lung. Lancet. (1983) 2:995-7. doi: 10.1016/S0140-6736(83)90981-9

318. Greos LS, Vichyanond P, Bloedow DC, Irvin CG, Larsen GL, Szefler SJ, et al. Methylprednisolone achieves greater concentrations in the lung than prednisolone. A pharmacokinetic analysis. Am Rev Respir Dis. (1991) 144:586-92. doi: 10.1164/ajrccm/144.3_Pt_1.586

319. Vichyanond P, Irvin CG, Larsen GL, Szefler SJ, Hill MR. Penetration of corticosteroids into the lung - evidence for a difference between 
methylprednisolone and prednisolone. J Allergy Clin Immunol. (1989) 84:867-73. doi: 10.1016/0091-6749(89)90381-3

320. M.G. Li S, Miller DD, Yates CR. Evaluation of AP-1 and NF-kB inhibitory potency for oral glucocorticoids. Pharm Sci. (2003) 5:Abstract R6173.

321. Croxtall JD, Van Hal PTW, Choudhury Q, Gilroy DW, Flower RJ. Different glucocorticoids vary in their genomic and non-genomic mechanism of action in A549 cells. Br J Pharmacol. (2002) 135:511-9. doi: 10.1038/sj.bjp.0704474

322. Nawab Q, Golden E, Confalonieri M, Umberger R, Meduri G. Corticosteroid treatment in severe community-acquired pneumonia: duration of treatment affects control of systemic inflammation and clinical improvement. Intensive care Med. (2011) 37:1153-554. doi: 10.1007/s00134-011-2274-5

323. Ewald H, Raatz H, Boscacci R, Furrer H, Bucher HC, Briel M. Adjunctive corticosteroids for pneumocystis jiroveci pneumonia in patients with HIV infection. Cochrane Database Syst Rev. (2015) 4:CD006150. doi: 10.1002/14651858.CD006150.pub2

324. Dinsen S, Baslund B, Klose M, Rasmussen AK, Friis-Hansen L, Hilsted L, et al. Why glucocorticoid withdrawal may sometimes be as dangerous as the treatment itself. Eur J Intern Med. (2013) 24:714-20. doi: 10.1016/j.ejim.2013.05.014

325. Schuetz P, Leuppi JD, Bingisser R, Bodmer M, Briel M, Drescher T, et al. Prospective analysis of adrenal function in patients with acute exacerbations of COPD: the reduction in the Use of Corticosteroids in Exacerbated COPD (REDUCE) trial. Eur J Endocrinol. (2015) 173:1927. doi: 10.1530/EJE-15-0182

326. Hakkinen PJ, Schmoyer RL, Witschi HP. Potentiation of butylatedhydroxytoluene-induced acute lung damage by oxygen. Effects of prednisolone and indomethacin. Am Rev Respir Dis. (1983) 128:648-51.

327. Kehrer JP, Klein-Szanto AJ, Sorensen EM, Pearlman R, Rosner MH. Enhanced acute lung damage following corticosteroid treatment. Am Rev Respir Dis. (1984) 130:256-61. doi: 10.1164/arrd.1984.130.2.256

328. Gagnon S, Boota AM, Fischl MA, Baier H, Kirksey OW, L. La voie, corticosteroids as adjunctive therapy for severe pneumocystis carinii pneumonia in the acquired immunodeficiency syndrome. A double-blind, placebo-controlled trial. N Engl J Med. (1990) 323:144450. doi: 10.1056/NEJM199011223232103

329. Steinberg KP, Hudson LD, Goodman RB, Hough CL, Lanken PN, Hyzy R, et al. Efficacy and safety of corticosteroids for persistent acute respiratory distress syndrome. N Engl J Med. (2006) 354:167184. doi: 10.1056/NEJMoa051693

330. Meduri GU, Bridges L, Siemieniuk RAC, Kocak M. An exploratory reanalysis of the randomized trial on efficacy of corticosteroids as rescue therapy for the late phase of acute respiratory distress syndrome. Crit Care Med. (2018) 46:884-91. doi: 10.1097/CCM.000000000000 3021

331. The Formulations Containing Benzyl Alcohol Should Not Be Used In Neonates. For Intravenous or Intramuscular Administration. SOLU-MEDROL $(\mathbb{R}$ (Methylprednisolone Sodium Succinate for Injection, USP) (2011). p. 118. Available online at: www.accessdata.fda.gov/drugsatfda_docs/label/2011/ 011856s103s104lbl.pdf (accessed October 1, 2017).

Disclaimer: The contents of this review do not represent the views of the U.S. Department of Veterans Affairs or the United States Government.

Conflict of Interest: The authors declare that the research was conducted in the absence of any commercial or financial relationships that could be construed as a potential conflict of interest.

Copyright (c) 2020 Meduri and Chrousos. This is an open-access article distributed under the terms of the Creative Commons Attribution License (CC BY). The use, distribution or reproduction in other forums is permitted, provided the original author(s) and the copyright owner(s) are credited and that the original publication in this journal is cited, in accordance with accepted academic practice. No use, distribution or reproduction is permitted which does not comply with these terms. 